\title{
Adjusting the Payroll Tax to Promote Longer Careers
}

\author{
John Laitner and Dan Silverman
}

Project \#: UM16-01 


\title{
Adjusting the Payroll Tax to Promote Longer Careers
}

\author{
John Laitner \\ University of Michigan \\ Dan Silverman \\ Arizona State University \\ Michigan Retirement Research Center \\ University of Michigan \\ P.O. Box 1248 \\ Ann Arbor, MI 48104 \\ www.mrrc.isr.umich.edu
}

(734) 615-0422

\section{Acknowledgements}

The research reported herein was performed pursuant to a grant from the U.S. Social Security Administration (SSA) funded as part of the Retirement Research Consortium through the University of Michigan Retirement Research Center Award RRC08098401. The opinions and conclusions expressed are solely those of the author(s) and do not represent the opinions or policy of SSA or any agency of the federal government. Neither the United States government nor any agency thereof, nor any of their employees, makes any warranty, express or implied, or assumes any legal liability or responsibility for the accuracy, completeness, or usefulness of the contents of this report. Reference herein to any specific commercial product, process or service by trade name, trademark, manufacturer, or otherwise does not necessarily constitute or imply endorsement, recommendation or favoring by the United States government or any agency thereof.

\section{Regents of the University of Michigan}

Michael J. Behm, Grand Blanc; Mark J. Bernstein, Ann Arbor; Shauna Ryder Diggs, Grosse Pointe; Denise Ilitch, Bingham Farms; Andrea Fischer Newman, Ann Arbor; Andrew C. Richner, Grosse Pointe Park; Ron Weiser, Ann Arbor; Katherine E. White, Ann Arbor; Mark S. Schlissel, ex officio 


\title{
Adjusting the Payroll Tax to Promote Longer Careers
}

\begin{abstract}
This paper analyzes a prospective Social Security reform that a number of authors have suggested, namely a payroll tax cut targeted on households near retirement. Our approach uses simulations of a life-cycle model, which we estimate from panel data. The simulations study effects on the labor force participation of older households. This paper specifically attempts to improve estimates of the model by incorporating newly available data, using both retirement and wealth accumulation data, and employing a formulation that avoids local optima to isolate only global maxima. Despite the changes, our results are generally consistent with earlier work, though they point to slightly more limited policy benefits.
\end{abstract}

\section{Citation}

Laitner, John, and Dan Silverman. 2017. “Adjusting the Payroll Tax to Promote Longer

Careers.” Ann Arbor, MI. University of Michigan Retirement Research Center (MRRC)

Working Paper, WP 2017-363.

http://www.mrrc.isr.umich.edu/publications/papers/pdf/wp363.pdf 


\section{Introduction}

Laitner and Silverman (LS) "Consumption, Retirement and Social Security: Evaluating the Efficiency of Reform that Encourages Longer Careers" [2012] uses a structural model to examine the costs and benefits of age-specific changes in the Social Security payroll tax. The authors find that substantial efficiency gains are possible from a payroll tax reduction targeted at ages near retirement, even if the tax reductions are coupled with increases at earlier ages that make the policy revenue neutral overall. The present paper attempts to re-examine the analysis with the aid of recent data and a more elaborate methodology — with the goal of developing an even stronger framework for policy analysis.

On the one hand, we modify Laitner and Silverman's modeling formulation. (i) The present paper explicitly solves the underlying life-cycle formulation for each household's optimal retirement age - checking sufficiency conditions at each observation rather relying on necessary conditions alone. The analysis is more accurate and more easily interpretable (see below) with this approach. (ii) This paper utilizes a treatment of agent lifetime earning profiles that allows heterogeneity in profile steepness. In the model, the steepness of a household's earnings profile is a key determinant of its optimal retirement age. We have access to panel data on earnings that is rich enough to facilitate a detailed study of this factor. (iii) The life-cycle model predicts a household's retirement age and its wealth accumulation as well. Both have significant roles in the policy evaluation literature. We have the data resources to study them jointly, and this paper utilizes a two-equation estimation approach to do so. New possibilities for model verification arise. (iv) We provide an upgraded treatment of selection, along the lines of Heckman's well-known 2-step method. We can handle cases in which a household dies or leaves the sample before retiring, and in which a household retires prior to the first survey wave but never specifies when.

On the other hand, the present paper seeks to take advantage of new data availability. Following the earlier work, we use the original HRS cohort, with survey respondents aged 51-61 in 1992. As before, we have (restricted) data that links Social Security earnings histories to men and women in the HRS. Instead of HRS survey data 1992-2002, however, this paper has waves for 1992-2014. Rather than having many households that have not yet retired, in the updated data virtually all careers are complete. The size of the sample with linked Social Security earnings histories is larger than before as well, with the administrative-record earnings data now covering 1951-2013. In addition, the present paper makes extensive use of Rand-processed HRS data files. This makes our work compatible with other studies using this well-known data.

We find that our life-cycle model parameter estimates are qualitatively similar to those in LS [2012]. They are not identical, however, and have tighter confidence intervals. Importantly, our analysis can be done using either data on retirement ages or household wealth accumulation, and we show that the two approaches yield similar outcomes. In 
fact, we show that using both data sources simultaneously yields more precise estimates than either generates individually.

Section 4 presents policy simulations. In times of lower fertility and longer life spans, the rate of labor force participation for older households is a topic of great interest. ${ }^{1}$ Lowering the payroll tax beyond some age — in effect, allowing a household's Social Security rights to become fully vested - has been proposed as a way of encouraging longer careers. ${ }^{2}$ A distinctive feature of our analysis is that it seeks to examine the consequences of such a reform using a model with estimated parameters. We find that our new parameter estimates are fully consistent with the idea that a policy with an age-varying payroll tax rate could promote higher labor force participation and greater economic efficiency. The increases in labor force participation that we find are slightly smaller than LS [2012], but we suggest explanations for the difference.

The organization of this paper is as follows. Section 1 sets up our modeling formulation. Section 2 reviews our data on household earnings and provides new regression results. Section 3 analyzes our complete life-cycle model. We provide structural-model parameter estimates, using both retirement and networth data. Section 4 briefly presents policy simulation results. Section 5 concludes the paper.

2. Model We begin with a model in which households face no uncertainty. Section $2 \mathrm{~B}$, however, presents a re-formulation that incorporates a random chance of disability.

2A. Certainty Specification We present our model and then characterize its solution.

If a household's consumption at age $s$ is $X_{s}$ and its size as measured in "equivalent adults" is $N_{s}$, its utility flow is

$$
U\left(X_{s}, s\right)= \begin{cases}\frac{1}{\gamma} \cdot N_{s} \cdot\left[\frac{\omega_{s} \cdot X_{s}}{N_{s}}\right]^{\gamma}, & \text { for } \gamma<1, \gamma \neq 0 \\ N_{s} \cdot \ln \left(\frac{\omega_{s} \cdot X_{s}}{N_{s}}\right), & \text { if } \gamma=0 .\end{cases}
$$

The parameter $\omega_{s}$, which captures the complementarity between time at home and consumption of goods, satisfies

$$
\omega_{s} \equiv \begin{cases}1, & \text { if } s<R \\ \omega, & \text { if } s \geq R,\end{cases}
$$

where $R$ is the household's age of retirement and

$$
\omega>1
$$

1 See, for example, the 2017 Report to the Social Security Advisory Board, http://ssab.gov/Details-Page/ArticleID/1180/Technical-Panel-on-Labor-ForceParticipation-A-Report-to-the-Board-June-2017.

2 E.g., Laitner and Silverman [2012], Goda et al. [2009], Burtless and Quinn [2002], and others. See also Banks and Diamond [2010], Erosa and Gervais [2002], Kremer [2002], Lozachmeur [2006], Weinzierl [2011], and others. 
measures the benefit of the extra time at home after retirement. We estimate the magnitude of $\omega$ below. The number of equivalent adults is

$$
N_{s}=1+\chi^{S}(s) \cdot \xi^{S}+\chi^{K}(s) \cdot \xi^{K},
$$

where $\chi^{S}(s)$ is 1 if a spouse is present at household age $s$ and 0 otherwise, and where $\chi^{K}(s)$ is the number of children present at age $s$. We estimate the spouse and "kid" weights, $\xi^{S}>0$ and $\xi^{K}>0$, respectively, below.

Isoelastic utility function (1) ensures homotheticity. In other words, households with above or below-average earnings should not necessarily have atypical retirement ages. Rather lifetime earnings profile shapes and household demographics should be the source of cross-sectional heterogeneity in retirement ages. We estimate the key parameter $\gamma$, which determines the model's intertemporal elasticity of substitution $1 /(1-\gamma)$.

The households in our model are couples. A household retires when its male spouse retires. "Age $s$ " is years since the male's birth. The household begins when $s=S$ and retires when $s=R$. The male dies when $s=T^{M}$. The female dies at age $T^{F}$. If the husband's age minus the wife's is $\Delta$, the household ends when $s=T$ with

$$
T \equiv \max \left\{T^{M}, T^{F}+\Delta\right\} .
$$

The household choice variables in our analysis are retirement age $R$ and consumption expenditure life trajectory $X_{s}, s \in[S, T]$.

For analytic convenience, we divide a household's life-cycle into 2 segments, preretirement and post-retirement. Our analysis works backward from the latter to the former, as in dynamic programming.

Post-Retirement. Consider a household's behavior after retirement. Let $A$ be the private networth the household has accumulated at retirement (including the capitalized present value, at $s=R$, of its private pensions). Given retirement age $R$, let $B(R)$ be the capitalized lifetime value of the household's Social Security and Medicare benefits, claimed at the "normal retirement age" (NRA) and age 65, respectively, but converted to present value at $s=0$. The after-tax interest rate is $r$, and the subjective discount rate is $\rho$. Household private networth at age $s$ is $A_{s}$. If the household's post-retirement utility is $V($.$) , then$

$$
\begin{gathered}
V\left(A+B(R) \cdot e^{r \cdot R}, R\right) \equiv \max _{X_{s}} \int_{R}^{T} e^{-\rho \cdot s} \cdot U\left(X_{s}, s\right) d s \\
\text { subject to: } \dot{A}_{s}=r \cdot A_{s}-X_{s}, \\
A_{R}=A+B(R) \cdot e^{r \cdot R} \quad \text { and } \quad a_{T} \geq 0 .
\end{gathered}
$$

There may be incentives to retire at particular ages implicit in some defined benefit private pension plans or employer-provided health insurance - e.g., Ippolito [1997]. Here

3 We treat the wife's earnings as exogenous. The model can be generalized to make spouses' retirement ages endogenous (e.g., House et al. [2007]). For the present estimation and policy simulations, that remains a topic for future research. 
we adopt the view that both employers and workers are heterogeneous in their preferences about retirement and that workers choose employers whose preferences match their own.

Pre-Retirement. Proceeding to the pre-retirement stage of life, let a household's age- $s$ male and female earnings flows be $y^{M}(s)$ and $y^{F}(s)$, respectively, where

$$
y^{M}(s) \equiv \begin{cases}e^{M}\left(k_{s}^{M}, s\right) \cdot w_{s} \cdot\left(1-\tau-\tau^{S S}\right), & \text { for } S \leq s<R \\ 0, & \text { for } s \geq R\end{cases}
$$

and

$$
y^{F}(s) \equiv e^{F}\left(k_{s}^{F}, s\right) \cdot w_{s} \cdot\left(1-\tau-\tau^{S S}\right) .
$$

The male spouse's "effective hours" or efficiency, is measured by $e^{M}$. Different households have different labor efficiencies, as explained below. In all cases, however, efficiency depends upon work experience, $k_{s}^{M}$, and age $s$. We assume a male spouse works steadily for $s \in[S, R)$. Thus,

$$
k_{s}^{M}=s-S \quad \text { for } \quad s \in[S, R) .
$$

The market wage per effective hour is $w_{s}$. The OASI, SSDI, and Medicare hospital payroll $\operatorname{tax}$ is $\tau$ (which includes both worker and employer shares). Our formulation subsumes income taxes on earnings in $\tau$.

Female-spousal labor force participation years and earnings are exogenous in this paper. Female effective hours depend on cumulative work experience $k_{s}^{F}$ and age. In practice, female careers sometimes have gaps of non-participation; thus, we cannot in general assume $k_{s}^{F}$ has the simple form of (7). As stated, in this paper female participation years and earnings are taken to be exogenous.

A household's lifetime utility is

$$
\begin{gathered}
\max _{R, X_{s}}{ }_{S}^{R} e^{-\rho \cdot s} \cdot U\left(X_{s}, s\right) d s+V A_{R}+B(R) \cdot e^{r \cdot R}, R \\
\text { subject to: } \quad \dot{A}_{s}=r \cdot A_{s}+y^{M}(s)+y^{F}(s)-X_{s}, \\
A_{S}=0 .
\end{gathered}
$$

Our model has neither inheritances nor bequests.

$\underline{\text { Analysis. }}$ For a given $R$, the pre and post-retirement problems are standard and concave. We have 
Proposition 1: Let a household have retirement age $R$. Then the household's optimal behavior satisfies

$$
\begin{gathered}
X_{s} / N_{s}=\left(X_{S} / N_{S}\right) \cdot e^{\frac{r-\rho}{1-\gamma} \cdot(s-S)} \quad \text { all } \quad s<R, \\
X_{R+} / N_{R+}=[\omega]^{\frac{\gamma}{1-\gamma}} \cdot\left(X_{R-} / N_{R-}\right), \\
X_{s} / N_{s}=\left(X_{R+} / N_{R+}\right) \cdot e^{\frac{r-\rho}{1-\gamma} \cdot(s-R)} \quad \text { all } \quad s \geq R .
\end{gathered}
$$

Proof: See LS [2012].

The idea is as follows. Let $R$ be given. Let $x_{s}^{*}$ be optimal consumption expenditure per equivalent adult. Then conventional first-order conditions from optimal control theory yield

$$
x_{s}^{*}=x_{0}^{*} \cdot e^{\frac{r-\rho}{1-\gamma} \cdot s} \quad \text { all } \quad s \in[S, T] .
$$

Optimality requires continuity of the Hamiltonian's costate variable. In our context, the costate variable equals $\partial U / \partial X_{s}$. When household composition changes, continuity across the change point yields (9) and (11). At retirement, higher leisure raises the value of consumption expenditures. Continuity of the costate then requires (10). Combining (9)(11), the optimal household expenditure trajectory $X_{s}^{*}$ obeys

$$
X_{s}^{*}= \begin{cases}N_{s} \cdot x_{s}^{*}, & \text { for } s<R, \\ N_{s} \cdot[\omega]^{\frac{\gamma}{1-\gamma}} \cdot x_{s}^{*}, & \text { for } s \geq R .\end{cases}
$$

In other words, given our equivalent-adults formulation, optimal household consumption changes in proportion to household composition over time. And, the increase in time at home after retirement requires a permanent proportional adjustment in consumption expenditure all $s \geq R$. We explain how to derive $x_{0}^{*}$ below.

Note that time at home and consumption expenditure are complementary in our setup. With more time at home after retirement, households naturally want more consumption expenditure. On the other hand, households want to smooth their total flow of "services," which are a composite of time at home and consumption expenditure. The desire to smooth makes a household want to have lower consumption expenditure after retirement. If the intertemporal elasticity of substitution (IES) is large - as when $\gamma \in(0,1)$ - the effect of complementarity dominates and the household chooses to raise its consumption expenditure after retirement (see (10)). If the IES is low - as when $\gamma<0$ - the desire to smooth dominates and a household lowers its consumption expenditure after retirement. When $\gamma=0$ - which is the logarithm case in (1) - complementarity and the desire to smooth exactly offset and a household does not change its consumption expenditure at retirement at all. 
Discussion. Our underlying framework is familiar, as the basic isoelastic preferences are very commonly employed to ensure homotheticity. Our interaction of leisure and consumption expenditure in (1) recognizes the importance for households of time away from work. As Proposition 1 shows, provided $\gamma=0$ households behaving optimally will want to adjust their consumption expenditure - downward if $\gamma<0$ or upward if $\gamma>0$ after retirement in response to the increase in leisure. See also LS [2012]. Gustman and Steinmeier [2004], for example, can be viewed as a special case that imposes $\gamma=0$.

Optimal Retirement. Next, we characterize the optimal choice of $R$.

Proposition 2: Suppose that $y^{F}(s)$ is exogenously given. Define

$$
\begin{gathered}
G(R) \equiv \frac{B^{\prime}(R) \cdot e^{r \cdot R}+y^{M}(R)}{X_{R-}}-(\Omega-1) \cdot \frac{1-\gamma}{\gamma}, \\
\Omega \equiv[\omega]^{\frac{\gamma}{1-\gamma}} .
\end{gathered}
$$

Then necessary conditions for an optimal retirement age $R=R^{*}$ are

$$
G\left(R^{*}\right)=0 \quad \text { and } \quad G^{\prime}\left(R^{*}\right) \leq 0 \text {. }
$$

Proof: See LS [2012].

The idea of Proposition 2 is as follows. Let $R=R^{*}$ and consider delaying retirement by $d R$. The gain in lifetime utility should equal the loss. The gain includes $U\left(X_{R}\right) d R$ less the value of resources expended, $U^{\prime}\left(X_{R-}\right) \cdot X_{R-} d R$, plus income and increased Social Security benefits, $U^{\prime}\left(X_{R-}\right) \cdot\left[y^{M}(R)+B^{\prime}(R) \cdot e^{r \cdot R}\right] d R$. And, similarly for the losses. Hence, using (10), we need ${ }^{4}$

$$
\begin{aligned}
& {\left[N_{R}\right]^{1-\gamma} \cdot\left[U\left(X_{R-}\right)-U^{\prime}\left(X_{R-}\right) \cdot X_{R-}+U^{\prime}\left(X_{R-}\right) \cdot\left(B^{\prime}(R) \cdot e^{r \cdot R}+y^{M}(R)\right)\right]} \\
& \quad=\left[N_{R}\right]^{1-\gamma} \cdot \Omega \cdot\left[U\left(X_{R-}\right)-U^{\prime}\left(X_{R-}\right) \cdot X_{R-}\right] .
\end{aligned}
$$

Dividing by $\left[X_{R-}\right]^{\gamma}$ and $\left[N_{R}\right]^{1-\gamma}$, we have

$$
\begin{gathered}
\frac{\frac{1-\gamma}{\gamma}+\frac{B^{\prime}(R) \cdot e^{r \cdot R}+y^{M}(R)}{X_{R-}}=\Omega \cdot \frac{1-\gamma}{\gamma} \Longleftrightarrow \frac{B^{\prime}(R) \cdot e^{r \cdot R}+y^{M}(R)}{X_{R-}}=(\Omega-1) \cdot \frac{1-\gamma}{\gamma} .}{4 \text { Although }} \quad d\left[B(R) \cdot e^{r \cdot R}\right] / d R=B^{\prime}(R) \cdot e^{r \cdot R}+r \cdot B(R) \cdot e^{r \cdot R},
\end{gathered}
$$

the second term on the RHS enters both sides of the next equation; hence, it cancels. Thus, it does not enter (14). 
The left-hand part of (15) is the first-order necessary condition. The right-hand part is the corresponding second-order necessary condition. Sufficiency, on the other hand, is not guaranteed: $B^{\prime}(R) \cdot e^{r \cdot R}+y^{M}(R)$ may well rise with $R$ at first but fall thereafter; $X_{R-}=x_{R-} \cdot N_{R}$ and $x_{R-}$ will rise with $R$ if $(r-\rho) /(1-\gamma)>0$; and, $N_{s}$ at age $s=R$ can (discontinuously) rise or fall with different values of $R$.

Solution. We can now complete our solution. Eqs (12)-(13) determine the shape of a household's optimal consumption expenditure trajectory up to a scaling factor $x_{0}^{*}$. Thus, we can determine a function $H(R)$ such that the lifetime cost, in present value at $s=0$, of the household's optimal consumption expenditure is

$$
\begin{gathered}
x_{0}^{*} \cdot H(R) \equiv x_{0}^{*} \cdot\left[{ }_{S}^{R} e^{z \cdot t} \cdot N_{t} d t+\Omega \cdot{ }_{R}^{T} e^{z \cdot t} \cdot N_{t} d t\right], \\
z \equiv \frac{r-\rho}{1-\gamma}-r .
\end{gathered}
$$

Let the present value at $s=0$ of the male and female spouses' lifetime earnings be $Y^{M}(R)$ and $Y^{F}$, respectively. Let $M$ be the lifetime value, in present value at $s=0$, of the household's Medicare benefits. Then for a given $R$,

$$
\begin{gathered}
Y^{M}(R)+Y^{F}+M+B(R) \cdot e^{r \cdot R}=x_{0}^{*} \cdot H(R) \Leftrightarrow \\
x_{0}^{*}=\frac{Y^{M}(R)+Y^{F}+M+B(R) \cdot e^{r \cdot R}}{H(R)} .
\end{gathered}
$$

Given $x_{0}^{*}=x_{0}^{*}(R)$, we can determine $X_{R-}=X_{R-}^{*}$ and, therefore, the function $G(R)$ from Proposition 2. Our procedure is to solve (15) and (17) simultaneously.

In practice, we set a grid of values for $R: R_{j}, j=1, \ldots, J$. For $R=R_{j}$, we use (12)(13) to set the shape of the optimal lifetime consumption expenditure trajectory. Then we derive $x_{0}^{*}$ from the household's lifetime budget constraint. We look for sign changes, $G\left(R_{j}\right)>0>G\left(R_{j+1}\right)$. For each sign change, we find the root $R \in\left(R_{j}, R_{j+1}\right)$. Such a root corresponds to a local maximum. We check lifetime utility for each local maximum. The global maximum establishes $R=R^{*}$.

2B. Specification with Uncertain Disability We next add disabilities that exogenously arise, with random timing. Assume disability compels retirement. Social Security Disability Insurance (SSDI) replaces part of the lost earnings, and we assume that private insurance covers the remainder. In other words, we assume full insurance.

Suppose there is a hazard $\lambda$ into disability. Take the simplest case, in which $\lambda$ does not vary with age. Assume the possibility of disability begins at age $\bar{S} \geq S$. If $P(t)$ is the probability of being disabled at age $t$,

$$
P(t)={ }_{\bar{S}}^{t} \lambda \cdot e^{-\lambda \cdot(s-\bar{S})} d s=1-e^{-\lambda \cdot(t-\bar{S})} .
$$


Insurance. Let the cost of private insurance be $K(R)$ if the household's planned retirement age is $R$. Assume the cost is measured in present value at age $s=0$ and is assessed as a one-time-only insurance premium at time $0 .{ }^{5}$ The premium has 4 components, as follows. Income Replacement Component The fully insured value of a household's male earnings, in present value at age 0 , assuming retirement age $R$, is

$$
Y^{M}(R)={ }_{S}^{R} e^{-r \cdot t} \cdot y_{t}^{M} d t .
$$

To eliminate uncertainty, private insurance must fully replace earnings lost to disability. Let the insurance cost for this be $I^{Y}(R)$. Then

$$
I^{Y}(R)={ }_{\bar{S}}^{R} \lambda \cdot e^{-\lambda \cdot(s-\bar{S})} \cdot{ }_{s}^{R} e^{-r \cdot t} \cdot y_{t}^{M} d t d s .
$$

Changing the order of integration,

$$
\begin{aligned}
I^{Y}(R) & ={ }_{\bar{S}}^{R} \quad{ }_{\bar{S}}^{t} \lambda \cdot e^{-\lambda \cdot(s-\bar{S})} e^{-r \cdot t} \cdot y_{t}^{M} d s d t \\
& ={ }_{\bar{S}}^{R} P(t) \cdot e^{-r \cdot t} \cdot y_{t}^{M} d t .
\end{aligned}
$$

Thus, $I^{Y}(R)$ is the product of the probability $P(t)$ of being disabled at $t$ and the present value of earnings lost, summed over the possible ages of disability.

SSDI Component The value of SSDI benefits, $I^{D}(R)$, offsets part of the earnings loss. (Hence, it enters the total insurance premium with a negative sign.) We assume that a household becoming disabled at age $s$ receives an SSDI benefit equaling its normal retirement age OASI benefit for its average earnings so far, without penalty for a short earnings history. Let $D(s)$ be the SSDI benefit flow if disability occurs at age $s$. The benefit flow disappears when the household reaches the Social Security normal retirement age (NRA), with OASI benefits commencing as a replacement. Thus,

$$
I^{D}(R)={ }_{\bar{S}}^{\min \{R, N R A\}} \lambda \cdot e^{-\lambda \cdot(s-\bar{S})} \cdot D(s) \cdot{ }_{s}^{N R A} e^{-r \cdot t} d t d s .
$$

Performing the integration with respect to $t$,

$$
I^{D}(R)={ }_{\bar{S}}^{\min \{R, N R A\}} \lambda \cdot e^{-\lambda \cdot(s-\bar{S})} \cdot D(s) \cdot \frac{e^{-r \cdot s}-e^{-r \cdot N R A}}{r} d s .
$$

OASI Adjustment Because a household's earnings tend to rise as its experience increases and because Social Security incorporates a correction for macroeconomic wage growth at

${ }^{5}$ Our model has no liquidity constraints; hence, the timing of the insurance premium makes little difference. 
claiming, a disabled household will almost invariably have lower OASI benefits once it reaches the NRA than otherwise. Let the insurance cost of offsetting any such reduction be $I^{B}(R)$. Following notation similar to the preceding section, let $B(R)$ be the present value at age 0 of the household's OASI benefits from the $N R A$ until $T$ if the household retires at age $R .{ }^{6}$ Let $B(s)$ be the same for benefits from the $N R A$ until $T$ if the household becomes disabled at age $s$. Then the age- 0 present value of the OASI correction is

$$
\begin{aligned}
I^{B}(R) & ={ }_{\bar{S}}^{R} \lambda \cdot e^{-\lambda \cdot(s-\bar{S})} \cdot[B(R)-B(s)] d s \\
= & P(R) \cdot B(R)-{ }_{\bar{S}}^{R} \lambda \cdot e^{-\lambda \cdot(s-\bar{S})} \cdot B(s) d s .
\end{aligned}
$$

As explained above, we expect $I^{B}(R)>0$ - so that $I^{B}(R)$ will tend to make a household's total insurance premium larger.

Consumption Turning to a household's consumption expenditure, Proposition 1 gives the optimal profile shape. The optimal shape includes a correction, via multiplication by $\Omega<1$, once a household has retired. A fully-insured household follows the optimal profile shape. If it plans to end its labor force participation at age $R$, its expected lifetime consumption expenditure is $x_{0}^{*} \cdot H^{*}(R)$, where

$$
\begin{aligned}
H^{*}(R) & \equiv{ }_{\bar{S}}^{R} \lambda \cdot e^{-\lambda \cdot(\bar{R}-\bar{S})} . \quad{ }_{S}^{\bar{R}} e^{z \cdot t} \cdot N_{t} d t+\Omega \cdot{ }_{\bar{R}}^{T} e^{z \cdot t} \cdot N_{t} d t d \bar{R} \\
& +[1-P(R)] \cdot{ }_{S}^{R} e^{z \cdot t} \cdot N_{t} d t+\Omega \cdot{ }_{R}^{T} e^{z \cdot t} \cdot N_{t} d t,
\end{aligned}
$$

with $P(t)$ as in (18) and $z$ as in (16). Changing the order of integration in the first term and letting $H(R)$ be as in (16), we have

$$
\begin{gathered}
H^{*}(R)=H(R)+J(R), \\
J(R) \equiv{ }_{\bar{S}}^{R}[\Omega-1] \cdot P(t) \cdot e^{z \cdot t} \cdot N_{t} d t .
\end{gathered}
$$

Recall that $\Omega<1$. Thus, the change of disability makes $H^{*}(R)<H(R)$. The reasoning is as follows: Disability affects consumption to the extent that it forces early retirement. The probability of disability at $t<R$ is $P(t)$. If disability occurs at age $t$, the height of the optimal consumption profile drops from $e^{z \cdot t} \cdot N_{t}$ to $\Omega \cdot e^{z \cdot t} \cdot N_{t}$.

6 Recall that we assume OASI benefits are always claimed when a household reaches the $N R A$. With certain age of death and no liquidity constraints, this entails no loss of generality. 
Solution. In the case of stochastic disability, our solution is as follows.

We replace (17) with

$$
Y^{M}(R)-\left[I^{Y}(R)-I^{D}(R)+I^{B}(R)\right]+Y^{F}+M+B(R)=x_{0}^{*} \cdot[H(R)+J(R)] .
$$

That determines $x_{0}^{*}$ :

$$
x_{0}^{*}=x_{0}^{*}(R)=\frac{Y^{M}(R)-\left[I^{Y}(R)-I^{D}(R)+I^{B}(R)\right]+Y^{F}+M+B(R)}{H(R)+J(R)} .
$$

The age- 0 insurance premium for retirement age $R$ is

$$
K(R) \equiv I^{Y}(R)-I^{D}(R)+I^{B}(R)+x_{0}^{*}(R) \cdot J(R) .
$$

Each term in (29) tends to be positive except $J(R)$. Finally, we need to amend the definition of $G(R)$ in Proposition 2 to

$$
G(R)=\frac{B^{\prime}(R) \cdot e^{r \cdot R}-K^{\prime}(R) \cdot e^{r \cdot R}+y^{M}(R)}{X_{R-}}-(\Omega-1) \cdot \frac{1-\gamma}{\gamma} .
$$

Think of the household's behavior as follows. Taking into account the cost of insurance, at $s=S$ a household determines its optimal retirement age $R^{*}$ from (15), with $G($.) as in (30). The household pays $K\left(R^{*}\right)$ to purchase private insurance - see (29). It then begins consuming according to (12)-(13). When it becomes disabled or reaches $s=R^{*}$, whichever is first, it switches its consumption expenditure to the second part of (13). Insurance enables the household simultaneously to balance its lifetime budget and follow its optimal consumption expenditure trajectory.

Notice that we could rather easily generalize the treatment of disability to consider multiple Poisson shocks. Thus, we could, for instance, have $\left(\lambda_{i}, \bar{S}_{i}\right)$ for $i=1,2$. The advantage would be as follows: In practice, the hazard to disability tends to rise with age. We could, therefore, have $\bar{S}_{1}<\bar{S}_{2}$. At early ages, the hazard to disability would be $\lambda_{1}$. However, after $\bar{S}_{2}$, it would be $\lambda_{1}+\lambda_{2}$.

3. Estimation Our estimation proceeds in 3 steps.

3A. Step-1: Analysis of Earnings In the first step, we estimate earnings dynamics equations for both spouses in each couple. There is a censoring problem in that basic administrative record earnings data is top coded at the Social Security cap. We use a Tobit maximum likelihood approach to cope with this issue. 
Data. We use SSA administrative lifetime earnings records to estimate earnings dynamics equations for men and for women. We estimate separate equations for 4 education groups: less than high school, high school, some college, and 4 years of college or more.

As stated, we study the original HRS cohort, aged 51-61 in 1992, using the HRS survey waves for 1992, 1994,..., 2014. We limit our attention to households that are couples in 1992 with both spouses alive and married only once. (If a couple divorces later, we drop it for subsequent dates.) For a link to administrative record earnings data, the agent must have granted permission for SSA to provide his/her Social Security earnings history to the HRS. Table A1 in the Appendix provides details on the samples.

The earnings data, taken exclusively from the administrative records, has the following special features:

Censoring Earnings are subject to the Social Security payroll tax only up to a statutory cap, and earnings histories only record amounts up to the latter. (The cap has, of course, changed over time.) Tables A2-A3 - see the Appendix - show the extent of the censoring is large. The earnings reports cover, at most, 1951-2013. We use "earnings adjusted for the taxable maximum." See "Health and Retirement Study Respondent Cross-Year Summary Earnings Data Description and Usage," Version 4.0, December 2014.

A second restricted data set, see "Health and Retirement Study Respondent CrossYear Earnings Data Description and Usage," Version 4.2, May 2015, contains supplementary W2 information for 1978 and beyond. In particular, it contains Medicare HI earnings. Through 1990, this measure of earnings has the same cap as the Social Security payroll tax. After 1990, however, the HI cap is higher. In fact, after 1994, there is no HI cap at all. For privacy reasons, even after 1994 a degree of censoring remains: HI earnings of $\$ 250-299,000$ are top-coded at $\$ 250,000 ; \$ 300-499,000$ at $\$ 300,000$; and, those above $\$ 500,000$ at $\$ 500,000$. Although the second data set does not add new observations, its higher top codes can augment the informational content of the basic files considerably in some cases.

Narrow Birth Range The initial HRS respondents were born 1931-41 (though our sample includes their spouses, who have a somewhat wider birth-date range). The age range is so narrow that an earnings dynamic model's typical treatment, in which earnings are a function of a polynomial in experience and of a system of year dummies, will be subject to multi-collinearity problems. Growth theory, on the other hand, suggests that the time trend of wages should mimic the macroeconomic growth of the average product of labor. In this vein, we deflate real earnings by the annual average level of labor productivity, which we measure with real private-sector value added divided by labor input (see historical multi-factor productivity tables, BLS.GOV/MFP/TABLES.HTM).

Tax Base Social Security earnings measure, of course, the Social Security tax base. The latter reflects factor payments to labor excluding employer Social Security taxes, employer paid pension contributions, and employer paid health insurance. To correct for the exclusions, we multiply our Social Security earnings by the year's ratio of total compensation (i.e., NIPA compensation of employees in domestic industries - NIPA Table 6.2, line 2) to wage and salary accruals (i.e., NIPA wage and salary accruals in domestic industries NIPA Table 6.3, line 2). 
Work Hours and Retirement The Social Security earnings histories may have gaps from non-FICA jobs - or from unemployment and other non-participation. For male earnings, we merely assume full participation from

$$
\text { starting age }=\max \{\text { years of education }+6,16\}
$$

until the age of retirement.

We determine the age of retirement from "Rand HRS Data Documentation," Version P, August 2016, Section I, and Section J. In Section I, we have a date for complete or partial retirement. We use the earlier of the two. If there is no such date, we take the last year for full-time work from Section $J$ as a lower bound for the household's retirement age - and the household enters our censored retirement category in step 2 below. Households with no retirement date in Section I and no record of full-time work in Section J are excluded. Other households that do not retire in sample are retained, however, and enter our censored-retirement category in step 2 as well.

Price Index We deflate earnings with the PCE deflator, using 1984 as the base year.

Male Earnings Dynamics Model. We use a standard earnings dynamics model to process the earnings data.

For males, we use the starting age from (31), calculating years of experience, $\exp _{i t}$, at that and all future ages. Let $y_{i t}$ be constant-dollar Social Security earnings, inclusive of benefits (see above). Our statistical model for Tables A2A-A2B - see Appendix - is

$$
\ln \left(y_{i t}\right)=f^{E}\left(\exp _{i t}\right)+\mu_{i}+\epsilon_{i t},
$$

where $f^{E}\left(\exp _{i t}\right)$, our "earnings" function, is a quadratic

$$
f^{E}(\exp ) \equiv \beta_{0}+\beta_{1} \cdot \exp +\beta_{2} \cdot \frac{e x p^{2}}{100} ;
$$

$\mu_{i}$ is the (random) individual effect for male $i$; and, $\epsilon_{i t}$ is an iid regression error.

We know which earnings observations are censored from top coding (including many top coded at the Social Security earnings "cap" - see above). Let "group 0" be uncensored observations, and "group 1" be censored. Let censored earnings be $\bar{y}_{i}$; let

$$
y_{i t}^{*} \equiv \begin{array}{ll}
y_{i t}, & \text { if group } 0 \\
\bar{y}_{i t}, & \text { otherwise; }
\end{array}
$$

and, let

$$
e_{i t} \equiv \ln \left(y_{i t}^{*}\right)-f^{E}\left(x_{i t}\right)-\mu_{i} .
$$

Then the likelihood function for Tables A2A-B is

$$
\ln (\mathcal{L})=\sum_{i} \ln _{-\infty}^{\infty} \phi\left(\mu_{i}, h_{\mu}\right) \cdot \prod_{0} \phi\left(e_{i t}, h_{\epsilon}\right) \cdot \prod_{1}\left[1-\Phi\left(e_{i t}, h_{\epsilon}\right)\right] d \mu_{i},
$$


where $\phi($.$) and \Phi($.$) are the normal density and cumulative normal distribution function,$ respectively,

$$
\begin{aligned}
& \phi(x, h) \equiv \frac{h}{\sqrt{2 \cdot \pi}} \cdot e^{-\frac{(x \cdot h)^{2}}{2}}, \\
& \Phi(x, h) \equiv{ }_{-\infty}^{x} \phi(\epsilon, h) d \epsilon .
\end{aligned}
$$

As indicated above, the observation counts in our tables show that censoring is a major factor for males in all education groups.

Table A2A uses all Social Security earnings figures; Table A2B uses only observations through the year before retirement (from full-time work) - to avoid a fractional last year or transitional job. For males, we exclude earnings observations less than 1000 times the year's minimum wage per hour. Thus, the samples in Tables A2A-D are slightly smaller than the number of linked male earnings records in Table A1. Table A2A is presented only for comparison; as stated above, in this paper's analysis, "retirement" is cessation of full-time work.

Tables A2C-D — see the Appendix — generalize statistical model (32) to

$$
\ln \left(y_{i t}\right)=f^{E}\left(\exp _{i t}\right)+\mu_{i}+\exp _{i t} \cdot \eta_{i}+\epsilon_{i t}
$$

The new specification allows heterogeneity in the steepness of individual earning profiles, which is potentially important for life-cycle wealth accumulation (see below). As before, $f^{E}(\exp )$ is quadratic in work experience exp, and $\epsilon_{i t}$ is iid normal. We assume $\left(\mu_{i}, \eta_{i}\right)$ is bivariate normal - with density $\bar{\phi}\left(\mu, \eta, h_{\mu}, h_{\eta}, \varrho\right)$. The random variables $\mu_{i}, \eta_{i}$, and $\epsilon_{i t}$ have mean 0 . Their precisions are $h_{\mu}, h_{\eta}$, and $h_{\epsilon}$, respectively. The correlation of $\mu_{i}$ and $\eta_{i}$ is $\varrho$. Defining

$$
e_{i t}^{*} \equiv \begin{cases}\ln \left(y_{i t}\right)-f^{E}\left(\exp _{i t}\right)-\mu_{i}-\exp _{i t} \cdot \eta_{i}, & \text { if group } 0 \\ \ln \left(\bar{y}_{i t}\right)-f^{E}\left(\exp _{i t}\right)-\mu_{i}-\exp _{i t} \cdot \eta_{i}, & \text { otherwise. }\end{cases}
$$

The likelihood is, integrating from $-\infty$ to $\infty$ for both $\mu_{i}$ and $\eta_{i}$,

$$
\begin{aligned}
& \ln (\mathcal{L})= \\
& \ln \quad \bar{\phi}\left(\mu_{i}, \eta_{i}, h_{\mu}, h_{\eta}, \varrho\right) \cdot \underbrace{}_{0} \phi\left(e_{i t}^{*}, h_{\epsilon}\right) \underbrace{}_{1}\left[1-\Phi\left(e_{i t}^{*}, h_{\epsilon}\right)\right] d \eta_{i} d \mu_{i} .
\end{aligned}
$$

To limit computational difficulties, we proceed as follows. We write $\bar{\phi}$ as the product of a marginal and a conditional density,

$$
\bar{\phi}\left(x, y, h_{x}, h_{y}, \varrho\right)=\phi\left(x, h_{x}\right) \cdot \frac{h_{y}}{\sqrt{1-\varrho^{2}}} \cdot e^{-\frac{\left(h_{y} \cdot[y-m]\right)^{2}}{1-\varrho^{2}}}
$$

with 


$$
m \equiv \varrho \cdot \frac{h_{x}}{h_{y}} \cdot x
$$

Our calculations then use a 5-point approximation of the inner integral of (36).

All of the coefficients in Tables A2A-D have large T-statistics. Table A2C imposes $\varrho=$ 0; Table A2D does not. The latter, more general formulation seems the most interesting.

In Table A2D, the correlation, $\varrho$, of $\mu$ and $\eta$ is always negative. However, its absolute magnitude is larger for lower education levels. For education group 1 , an individual $i$ tends to have a high starting value $\mu_{i}$ and a low intra-lifetime growth rate $\eta_{i}$, or a low starting value and a high growth rate. It is as if some jobs require learning at the beginning but ultimately pay more, whereas other jobs have more favorable starting pay but less room for growth. Assume individual outcomes $\left(\mu_{i}, \eta_{i}\right)$ reflect preferences upon starting work. An individual's choice is important to our analysis: those selecting a high-growth career will tend to be nearer to their peak earnings as they reach older ages, and they are, according to our model, likely to want to retire later (recall Proposition 2).

For education group 4, on the other hand, the absolute magnitude of the correlation $\varrho$ is lower. Evidently, some college graduates have, regardless of their starting earnings, a steeper lifetime earnings trajectory than others. We might think of those with steep trajectories as beginning their careers with a technical job but subsequently moving to a managerial position. An agent with a low $\eta_{i}$, in contrast, may never leave his technical job. Education categories 2-3 may manifest convex combinations of these paradigms.

Female Earnings Dynamics Model. With many more gaps in lifetime earnings trajectories, females are more challenging to model. This paper limits its analysis of female earnings to the specification above with 2 error components. We assume that shorter earnings histories reflect shorter careers. In determining a female's work experience $\exp _{i t}$, therefore, we count only years with positive administrative-record earnings. We exclude only years with earnings less than 500 times the year's minimum wage per hour. Comparing our measure of experience with self-reported lifetime years in the labor force, the agreement is good in most cases.

In comparison with males (e.g., Table A3A versus A2A), the female constant, $\beta_{0}$, is lower; female earnings profiles peak at earlier levels of experience (see $e x p^{*}$ ); and, the female start-to-peak gain in earnings is substantially lower (c.f., $y^{*} / y_{0}$ ).

This paper focuses on male retirement, treating female earnings as exogenous. ${ }^{7}$

3B. Step-2: Reduced-Form Analysis of Retirement Ages In our second step, we estimate a linearized, reduced-form model of each household's retirement. Data issues such as early retirement due to disability lead to censoring problems. Again, we use a Tobit maximum likelihood approach.

7 LS [2012] treat the case with joint retirement of both spouses. See also, for example, Gustman and Steinmeier [2000]. 
Likelihood Function. We face 3 types of censoring. First, our retirement data comes from HRS (biannual) surveys 1992-2014. Since each HRS couple has at least one member 51-61 in 1992, a nontrivial number of our males retire before 1992. Sometimes we have a respondent-reported male retirement date before 1992. Other times, not. If not, we assume a male who is retired (or "out of the labor force") in the first survey has a retirement date censored below 1992. We call this "case-1 censoring."

Second, some respondents leave our sample after 1992 but prior to retiring (either through attrition from the HRS, divorce or remarriage after widowing, or premature death). Moreover, although the HRS does not register a retirement age for every male, for some missing values we can determine a last survey wave with full-time employment. We treat these cases as having a career length censored above the last observation with full-time work. These are households with "case-2 censoring."

Third, some respondents exit the labor force due to disability, or retire but categorize themselves as disabled prior to it or within one survey wave thereafter. We treat their intended retirement age as censored above at the disability age. These are households with "case-3 censoring."

Respondents with a valid retirement date, and a career not interrupted by disability, are uncensored - our "case 0" households.

Our analysis is as follows. Letting $R_{i}$ be the (male) retirement age in case- 0 , and letting $f_{i}^{T}(\alpha)$ be the Tobit linearized reduced-form model, with parameter vector $\alpha$, we have

$$
R_{i}=f_{i}^{T}(\alpha)+\nu_{i} \quad \text { for case } 0 .
$$

In other cases, let $\bar{R}_{i}$ be the level of the censored retirement age. Let $h_{\nu}$ be the precision for the regression error $\nu$, i.e., $h_{\nu}=1 / \sigma_{\nu}$. Define

$$
v_{i} \equiv \begin{cases}R_{i}-f_{i}^{T}(\alpha), & \text { for } i \text { in group } 0, \\ \bar{R}_{i}-f_{i}^{T}(\alpha), & \text { otherwise. }\end{cases}
$$

Continuing with the normal density and cumulative norm $\phi($.$) and \Phi($.$) , respectively, as$ above, the Tobit likelihood function is then

$$
\mathcal{L}={ }_{0} \phi\left(v_{i}, h_{\nu}\right) \cdot{ }_{1} \Phi\left(v_{i}, h_{\nu}\right) \cdot{ }_{2}\left[1-\Phi\left(v_{i}, h_{\nu}\right)\right] \cdot{ }_{3}\left[1-\Phi\left(v_{i}, h_{\nu}\right)\right] .
$$

Results. Tables A4A-D - see Appendix - present outcomes. Tables A4A-B use the male earnings dynamics results from Table A2B. Tables A4C-D use the male earnings equations from Table A2D. Tables A4A-D use the female earnings regressions from Table A3B.

Table A4D seems the most sophisticated and the most interesting. In Table A4D, there are 3 highly (statistically) significant regressors: (i) the constants for the different education groups; (ii) the dummy for "any years of self-employment" 1992-2014; and, 
(iii) the mean error component for the steepness of a household's (male) lifetime earnings profile, $E\left[\eta_{i}\right] .^{8}$

As all regressors beyond the first in Table A4D are deviations from their mean, the Tobit's constant gives the average (male) retirement age. The average retirement age rises with education - though surprisingly modestly. While, for example, all group-4 households have 4 or more years of education than group 2, their average retirement age is only 1-1.5 years higher. Males with the least education have, on average, the longest careers. Note that we could anticipate that our structural model also manifests this property: a life-cycle model tends to highlight the importance of demographic factors, and, if household $i$ has more years of education but roughly the same projected life span as household $j$, the structural model might well predict a later retirement age for $i$ but a shorter overall career.

As we might expect from the literature, having access to self-employment has a positive effect on retirement age (though only marginally so for education group 4). Presumably self-employment has many amenities (e.g., flexible work hours) that older workers find attractive.

The maximum $E\left[\eta_{i}\right]$ is 0.03-0.04; hence, households with the highest earnings growth rates (with respect to age) retire 1.5-3.0 years above the average. ${ }^{9}$ The Table-A4B coefficients on $E\left[\eta_{i}\right]$ are highly statistically significant and the implied role for $E\left[\eta_{i}\right]$ is fully consistent with our structural model. In particular, Proposition 2 shows that a household retires when the marginal value of lost earnings equals the lost utility from postponing access to greater leisure. A steep lifetime earnings profile makes the former greater, increasing the optimal retirement age.

Comparing results to Table $\mathrm{A} 4 \mathrm{~B}$, in the latter the roles of the constants and selfemployment are similar. Without $E\left[\eta_{i}\right], E\left[\mu_{i}\right]$, the general relative level of male earnings seems positively related to later retirement. However, the effect of $E\left[\mu_{i}\right]$ disappears in Table A4D. In neither table does female relative earning ability affect male retirement age noticeably. Our model has homothetic preferences and, as is the outcome in Table A4D, we would not expect the level of earnings, as governed by $E\left[\mu_{i}\right]$, to affect $R^{*}$.

Other regressors in Table A4D have marginal or ambiguous roles. The model suggests that a household with more children - leading to a higher marginal utility of household

8 Let $\vec{y}_{i}$ be the vector of observations on male $i$ earnings. Let the integrand in (37) be $\Upsilon\left(\mu, \eta, \vec{y}_{i}\right)$, and let

$$
\bar{\Upsilon}\left(\eta, \vec{y}_{i}\right) \equiv \Upsilon\left(\mu, \eta, \vec{y}_{i}\right) d \mu
$$

Then we determine $E\left[\eta_{i}\right] \equiv E\left[\eta \mid \vec{y}_{i}\right]$ from

$$
E\left[\eta_{i}\right]=\quad \eta \cdot \bar{\Upsilon}\left(\eta, \vec{y}_{i}\right) d \eta / \quad \bar{\Upsilon}\left(\eta, \vec{y}_{i}\right) d \eta
$$

9 Recall that the macroeconomic growth rate is the same for all households in our earnings dynamics analysis. 
consumption expenditure - should work longer. While that seems true in the case of group 4, its statistical significance is modest. What is more, the opposite outcome holds for group 2. Future work incorporating endogenous female labor-force participation might yield more easily interpretable results. ${ }^{10}$

Similarly, having had a bridge job (i.e., having access to a bridge job) is similarly modestly significant for group 4 - where it seems to shorten full-time work. On the other hand, it is not significant for other education groups.

Birth-year dummies are significantly positive, and generally manifest a declining pattern, for group 1. But their role seems negligible for groups 2-4. Perhaps our treatment of case-1 censoring is least effective for group 1.

3C. Step-3: Structural Model In the third empirical step, we estimate Section-2's structural model.

The structural model is nonlinear and leads to a regression equation

$$
\widetilde{R}_{i}=f_{i}^{R}(\theta)+\epsilon_{i}^{R}
$$

where $\theta$ is the vector of parameters and $\epsilon^{R}$ is the regression error. We first develop a correction procedure for selection problems identified in step 2 . That provides the dependent variable $\widetilde{R}_{i}$.

Corrections for Censoring. Step 2 identified 3 types of censoring in our retirement data. Unless we make a correction in (40), our estimates of the structural parameter vector $\theta$ will suffer from selection biases.

We use our step-2 reduced-form model to generate the new dependent variable $\widetilde{R}_{i}$. For case 0 from step 2, no correction is necessary. For $i$ with case- 1 censoring, we observe $\bar{R}_{i}$ with

$$
\bar{R}_{i} \geq f_{i}^{T}(\alpha)+\nu_{i} \Longleftrightarrow \nu_{i} \leq \bar{R}_{i}-f_{i}^{T}(\alpha)
$$

Then letting $\nu^{*} \equiv h_{\nu} \cdot \nu$, we $\operatorname{set}^{11}$

$$
\begin{aligned}
\widetilde{R}_{i} & \equiv f_{i}^{T}(\alpha)+E\left[\nu_{i} \mid \nu_{i} \leq \bar{R}_{i}-f^{T}(\alpha)\right] \\
& =f^{T}(\alpha)+\frac{\int_{-\infty}^{\bar{R}_{i}-f_{i}^{T}(\alpha)} h_{\nu} \cdot \nu \cdot \phi\left(h_{\nu} \cdot \nu\right) d \nu}{\int_{-\infty}^{\bar{R}_{i}-f_{i}^{T}(\alpha)} h_{\nu} \cdot \phi\left(h_{\nu} \cdot \nu\right) d \nu}
\end{aligned}
$$

10 E.g., House et al. [2008].

11 Using the notation for the standardized normal and cumulative normal above, note that

$$
d \phi=-\nu \cdot \phi(\nu) d \nu
$$




$$
\begin{aligned}
& =f^{T}(\alpha)+\frac{1}{h_{\nu}} \cdot \frac{h_{\nu} \cdot\left[\bar{R}_{i}-f_{i}^{T}(\alpha)\right]}{h_{\nu} \cdot\left[\bar{R}_{i}-f_{i}^{T}(\alpha)\right]} \phi\left(\nu^{*}\right) d \nu^{*} \\
& =f_{i}^{T}(\alpha)-\frac{1}{h_{\nu}} \cdot \frac{\phi\left(h_{\nu} \cdot\left[\bar{R}_{i}-f_{i}^{T}(\alpha)\right]\right)}{1-\Phi\left(-h_{\nu} \cdot\left[\bar{R}_{i}-f_{i}^{T}(\alpha)\right]\right)}
\end{aligned}
$$

In the same vein, for $i$ in step-2 censoring cases 2-3, we observe $\bar{R}_{i}$ with

$$
\bar{R}_{i} \leq f_{i}^{T}(\alpha)+\nu_{i} \Longleftrightarrow \nu_{i} \geq \bar{R}_{i}-f_{i}^{T}(\alpha) .
$$

We set

$$
\begin{aligned}
\widetilde{R}_{i} & \equiv f_{i}^{T}(\alpha)+E\left[\nu_{i} \mid \nu_{i} \geq \bar{R}_{i}-f^{T}(\alpha)\right] \\
& =f_{i}^{T}(\alpha)+\frac{1}{h_{\nu}} \cdot \frac{\phi\left(h_{\nu} \cdot\left[\bar{R}_{i}-f_{i}^{T}(\alpha)\right]\right)}{1-\Phi\left(h_{\nu} \cdot\left[\bar{R}_{i}-f_{i}^{T}(\alpha)\right]\right)} .
\end{aligned}
$$

Summarizing,

$$
\widetilde{R}_{i} \equiv \begin{cases}R_{i}, & \text { for } i \text { in case 0, } \\ f_{i}^{T}(\alpha)-\frac{1}{h_{\nu}} \cdot \frac{\phi\left(-h_{\nu} \cdot\left[\bar{R}_{i}-f_{i}^{T}(\alpha)\right]\right)}{1-\Phi\left(-h_{\nu} \cdot\left[\bar{R}_{i}-f_{i}^{T}(\alpha)\right]\right)}, & \text { for } i \text { in case 1, } \\ f_{i}^{T}(\alpha)+\frac{1}{h_{\nu}} \cdot \frac{\phi\left(h_{\nu} \cdot\left[\bar{R}_{i}-f_{i}^{T}(\alpha)\right]\right)}{1-\Phi\left(h_{\nu} \cdot\left[\bar{R}_{i}-f_{i}^{T}(\alpha)\right]\right)}, & \text { for } i \text { in cases 2-3. }\end{cases}
$$

Econometric Specification. The structural model contains 3 types of terms.

Terms of Type 1 The first type is based upon Proposition 2 and uses CEX consumption data. Let average per capita consumption expenditure for age $s$ and time $t$ be $c_{s t}$. As in LS [2012], we normalize each year's data to match NIPA aggregates. From (12)-(13), a household's age- $s$ optimal consumption expenditure is $X_{s}^{*}$ with

$$
\ln \left(X_{s}^{*}\right)= \begin{cases}\ln \left(N_{s}\right)+\ln \left(x_{0}^{*}\right)+\frac{r-\rho}{1-\gamma} \cdot s, & s<R, \\ \ln \left(N_{s}\right)+\frac{\gamma}{1-\gamma} \cdot \ln (\omega)+\ln \left(x_{0}^{*}\right)+\frac{r-\rho}{1-\gamma} \cdot s, & s \geq R .\end{cases}
$$

From (3),

$$
\ln \left(N_{s}\right)=\ln \left(1+N_{s}-1\right) \approx N_{s}-1=\chi^{S}(s) \cdot \xi^{S}+\chi^{K}(s) \cdot \xi^{K} .
$$

Similarly,

$$
\ln \left(X_{s}^{*}\right) \approx X_{s}^{*}-1 .
$$

Let $\chi^{S}(s)$ be 1 if the household has a spouse present at age $s$ and 0 otherwise; let $\chi^{K}(s)$ be the number of kids present; and, let $\chi^{R}(s)$ be 1 if the household is retired and 0 otherwise. Let 


$$
\Delta \chi^{S}(s) \equiv \chi^{S}(s+1)-\chi^{S}(s)
$$

etc. Then we have an approximation

$$
\begin{gathered}
\Delta X_{s}^{*}=\beta_{1}+\beta_{2} \cdot \Delta \chi^{S}(s)+\beta_{3} \cdot \Delta \chi^{K}(s)+\beta_{4} \cdot \Delta \chi^{R}(s), \\
\beta^{T} \equiv \frac{r-\rho}{1-\gamma}, \xi^{S}, \xi^{K}, \frac{\gamma}{1-\gamma} \cdot \ln (\omega) .
\end{gathered}
$$

Returning to the CEX data, index observation $c_{s t}$ as $c_{i}$, where $\Delta c_{i}=c_{s+1, t+1}-c_{s t}$, etc. Then from the logic of (42),

$$
\begin{gathered}
y_{i} \equiv \Delta c_{i}=x_{i}^{T} \cdot \beta+\Delta \nu_{i}, \quad i \in C E X, \\
x_{i}^{T} \equiv 1, \Delta \chi^{S}(i), \Delta \chi^{K}(i), \Delta \chi^{R}(i),
\end{gathered}
$$

where $\nu_{i}$ is iid measurement error for the level of $c_{i}$.

Stacking rows (43) into a vector, we have a band symmetric variance matrix that we can invert. Taking a Cholesky factorization, we can transform (43) to a homoscedastic form

$$
\bar{y}_{i}=\bar{x}_{i}^{T} \cdot \beta+\epsilon_{i}, \quad i \in C E X .
$$

Terms of Type 2-3 Let $H R S^{R}=H R S^{A}=H R S$ be the set of HRS households with both retirement and networth at year 1992 data. Given $\beta$ and $\gamma=\gamma^{R}$, our model and the data can be solved for an optimal retirement age $R_{i^{\prime}}$ for each household:

$$
\tilde{R}_{i^{\prime}}=f_{i^{\prime}}^{R}\left(\beta, \gamma^{R}\right)+\epsilon_{i^{\prime}}^{R}, \quad i^{\prime} \in H R S^{R} .
$$

Similarly, if $A_{i^{\prime \prime}}$ is a household's networth in 1992 and we set $\gamma=\gamma^{A}$, then

$$
A_{i^{\prime \prime}}=f_{i^{\prime \prime}}^{A}\left(\beta, \gamma^{A}\right)+\epsilon_{i^{\prime \prime}}^{A}, \quad i^{\prime \prime} \in H R S^{A} .
$$

Notice that our corrections for selection tend to make $\epsilon^{R}$ heteroscedastic and that $\epsilon^{R}$ and $\epsilon^{A}$ may well be correlated.

Estimation. We follow Gallant [1987].

Stage 1 We obtain stage-1 estimates of

$$
\theta \equiv\left(\beta^{T}, \gamma^{R}, \gamma^{A}\right)
$$

as follows. Define

$$
q_{i} \equiv \begin{cases}\bar{y}_{i}-\bar{x}_{i}^{T} \cdot \beta, & \text { for } i \in C E X \\ \tilde{R}_{i}-f_{i}^{R}\left(\beta, \gamma^{R}\right), & \text { for } i \in H R S^{R} \\ A_{i}-f_{i}^{A}\left(\beta, \gamma^{A}\right), & \text { for } i \in H R S^{A}\end{cases}
$$




$$
Z_{i} \equiv \begin{cases}\left(\bar{x}_{i}^{T}, 0,0\right)^{T}, & \text { for } i \in C E X \\ (\tilde{0}, 1,0)^{T}, & \text { for } i \in H R S^{R} \\ (\tilde{0}, 0,1)^{T}, & \text { for } i \in H R S^{A}\end{cases}
$$

Note that $Z_{i} \in R^{6}$ all $i$. For any symmetric, positive definite, $6 \times 6$ matrix $V$, define

$$
\mathcal{S} \theta, V \equiv \frac{1}{2} \cdot{ }_{i} \quad q_{i} \otimes Z_{i}{ }^{T} \cdot V^{-1} . \quad{ }_{i} q_{i} \otimes Z_{i} .
$$

Setting $V$ to the identity matrix, the stage- 1 estimate of $\theta$ is

$$
\hat{\theta} \equiv\left(\hat{\beta}, \hat{\gamma}^{R}, \hat{\gamma}^{A}\right)=\arg \min _{\theta} \mathcal{S}(\theta, I)
$$

See below.

The covariance matrix for $\hat{\theta}$ is as follows. Let $\hat{V}=V$ be zeros except for $4 \times 4$ and $2 \times 2$ matrices, $\bar{V}$ and $\overline{\bar{V}}$ on its principal diagonal. The $4 \times 4$ matrix is

$$
\bar{V} \equiv\left[\sigma^{C E X}\right]^{2} \cdot{ }_{i} \bar{x}_{i} \cdot \bar{x}_{i}^{T}
$$

where $\sigma^{C E}$ is the sampling variance from OLS regression (44). The $2 \times 2$ matrix is

$$
\overline{\bar{V}} \equiv \# H R S \cdot\left(\begin{array}{ll}
\sigma_{R R} & \sigma_{R A} \\
\sigma_{R A} & \sigma_{A A}
\end{array}\right)
$$

the elements being the sampling covariances from the residuals $q_{i^{\prime}}$ and $q_{i^{\prime \prime}}$, respectively, and \#HRS, the HRS sample size. We have

$$
\hat{V}=\left(\begin{array}{cc}
\bar{V} & \tilde{0} \\
\tilde{0} & \overline{\bar{V}}
\end{array}\right)
$$

As stated, our corrections for selection can render $\epsilon^{R}$ heteroscedastic. Given the simple nature of our instruments $Z_{i}$, however, $\overline{\bar{V}}$ gives us a heteroscedastic invariant covariance matrix estimator below (see White [1980], Gallant [1987, p.222]).

Letting the $6 \times 6$ matrix $Q$ have column $j$

$$
\frac{\partial q_{i}}{\partial \theta_{j}} \otimes Z_{i}
$$

the covariance matrix for $\hat{\theta}$ is

$$
\left.\mathcal{C}=Q^{T} \cdot[\hat{V}]^{-1} \cdot Q\right]^{-1}
$$

We can test $\hat{\gamma}^{R}=\hat{\gamma}^{A}$. This hypothesis is substantively important - see below. 
Stage 2 We next impose $\gamma=\gamma^{R}=\gamma^{A}$. We continue with $V=\hat{V}$, as above, which remains a consistent estimate.

In Stage 2, we solve

$$
\begin{gathered}
\max _{\theta} \mathcal{S}(\theta, \hat{V}), \\
\text { subject to: } \theta_{5}=\theta_{6} .
\end{gathered}
$$

We use Newton's method, as in Gallant [1989, p.434].

Given the constraint in (49), we are now estimating 5 parameters. In other words, we are only estimating the constrained parameter vector

$$
\theta^{c} \equiv\left(\beta^{T}, \gamma\right) \in R^{5}
$$

Call our estimate $\widehat{\theta^{c}}$.

To derive the covariance matrix of the new parameter vector, we need to modify (48). To do so, we substitute a matrix $Q^{c}$ for $Q$. The matrix $Q^{c}$ is $6 \times 5$. It has the same first 4 columns as $Q$. The fifth column of $Q^{c}$, however, is the sum of the fifth and sixth columns of $Q$, that is to say it is

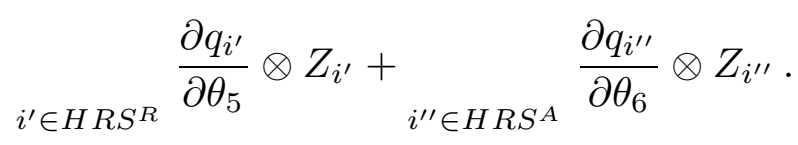

As stated, we use the same $\hat{V}$ as before. Call the new covariance matrix, say, $\mathcal{C}^{c}$.

Data. Our CEX data is exactly the same as LS [2012] (see also Laitner and Silverman [2005]). The number of CEX observations is 765. The $H R S^{R}$ sample has been described above. It has 1634 observations. Table 1 presents statistics. The table's first 2 rows refer to $\tilde{R}$, as in (40). Although we correct for 3 types of censoring, the table's Addendum shows that the fraction of the sample that is censored is relatively small - less than $20 \%$ of the total (in contrast to LS [2012] where over half the observations are censored). As noted above, the sample is limited to households that are couples in 1992. The retirement age refers to men. We exclude cases with retirement prior to age 51 . We assume men die at (the beginning of) age 75; hence, there are no retirement ages beyond that.

The $H R S^{A}$ sample covers the same households as $H R S^{R}$. None of the networth observations are censored. ${ }^{12}$ All of the figures are current values in 1992 (in terms of 1984 dollars). We use Rand HRS "financial and housing wealth," including secondary residence, 1992 wave. ${ }^{13}$ This includes primary and secondary residence; other real estate; vehicles; own business; IRAs; corporate stocks and bonds; checking, saving, and money market accounts; CDs and government bonds; other savings; less debts and mortgages. We add employer provided pensions, DB and DC, both reported and imputed, in present value

12 Note: for regression (47), we solve the model for a household's optimal retirement age and then compute the corresponding $A_{i^{\prime \prime}}$. Only the latter is used in analysis of (47).

13 See variable H1ATOTB in Rand HRS Data Documentation: Version P, 2016, at http://www.rand.org/labor/aging/dataprod/hrs-data.html. 
1992, with 1984 dollars. DB pension equity is prorated to 1992, based on work to date (in 1992). ${ }^{14}$ As employer provided pensions are pre-tax dollars in practice, we subtract income taxes for comparability with the model. The networth data excludes capitalized Social Security and Medicare benefits, as our model incorporates the latter two separately. Table 1 presents statistics on the sample. Obtaining detailed DB, as well as DC, pension data is an important innovation of the HRS - and we can see the significance of pensions in the magnitude of $A_{i^{\prime \prime}}$.

The analysis also considers a winsorized sample, which trims the top and bottom $1 \%$ of the wealth observations. Winsorization is often used as a protection against outliers, from, say, errors in the data. In our case, the top wealth observations may also reflect estatebuilding, which is outside the scope of our model. (Indeed, the excluded observations include wealth holdings roughly in the range $\$ 2.5-5$ mil., all of which exceed what the model generates.) The low-wealth exclusions all have negative values, which may reflect bankruptcy options in practice, which the model lacks.

Outcomes. Table 2 presents results. Table $2 \mathrm{~A}$ uses a hazard to disability of $1 \% / \mathrm{yr}$, starting at (the end of) age 50 . Table $2 \mathrm{~B}$ uses a $2 \% /$ yr hazard starting at age 60 (cf., LS [2012, Table 3]). Table 2C sets the disability hazards to 0; it is included for the sake of comparison.

Stage 1 and stage 2 can be interpreted as follows. In stage 1 , the model is exactly identified, and we can characterize the solution to (47) fully. In particular, the OLS estimator in (44), say, $\widehat{\beta} \in R^{4}$, solves

$$
\underset{i \in C E X}{ } q_{i} \otimes Z_{i}=\tilde{0} \in R^{4} .
$$

Given $\widehat{\beta}$, choose $\widehat{\gamma}^{R}$ to make

$$
\underset{i^{\prime} \in H R S^{R}}{ } q_{i^{\prime}}=0 \in R^{1} .
$$

And, given $\widehat{\beta}$, choose $\widehat{\gamma}^{A}$ to make

$$
\underset{i^{\prime \prime} \in H R S^{A}}{ } q_{i^{\prime \prime}}=0 \in R^{1} .
$$

Then the criterion of $(47)$ is 0 , its minimum. As these steps show, $\left(\widehat{\beta}, \widehat{\gamma}^{R}\right)$ provides an estimator for the system (44)-(45), whereas $\left(\widehat{\beta}, \widehat{\gamma}^{A}\right)$ does the same for the system of (44) and (46). In stage 2, we estimate (44)-(46) jointly by constraining $\gamma^{R}=\gamma^{A}=\gamma$. In stage

14 See Health and Retirement Study, Imputations for Pension Wealth, 2006, Data Description and Usage, at http://hrsonline.isr.umich.edu/modules/meta/xyear/ipw/desc/imppenwdd.pdf?.ga= 2.200940582.943205656.1499911168-2032089123.1438294228. And, Pension Wealth 1992 \& 1998, Documentation Database Codebook Generator (v1.1) 12/12/2006 at http://hrs.isr.umich.edu/documentation/codebooks. 
Table 1. Retirement Age $(\tilde{R})$ and Networth (1000s 1984 dollars) $1992(A)$ for HRS Couples 1992-2014

\begin{tabular}{|c|c|c|c|c|c|c|}
\hline Variable & Mean & $\begin{array}{l}\text { Coef. } \\
\text { Var. }\end{array}$ & Median & $\begin{array}{l}\text { Inter- } \\
\text { quartile } \\
\text { Spread }\end{array}$ & $\begin{array}{l}\text { Min- } \\
\text { imum }\end{array}$ & $\begin{array}{l}\text { Max- } \\
\text { imum }\end{array}$ \\
\hline$\tilde{R} \underline{a} /$ & 62.53 & 0.08 & 62.42 & 5.42 & 51.00 & 75.00 \\
\hline$\tilde{R}$ winsorized & 62.52 & 0.08 & 62.42 & 5.42 & 51.00 & 75.00 \\
\hline$A$ & 277.49 & 1.56 & 160.93 & 248.29 & -74.14 & 4929.21 \\
\hline $\begin{array}{c}A \text { excluding } \\
\text { employer pension } \underline{b} /\end{array}$ & 215.03 & 1.80 & 108.48 & 172.03 & -75.45 & 4743.95 \\
\hline$A$ winsorized & 248.49 & 1.13 & 161.12 & 244.22 & -0.26 & 2159.31 \\
\hline $\begin{array}{l}A \text { winsorized } \\
\text { excl. empl. pension } \underline{b} /\end{array}$ & 189.36 & 1.33 & 108.59 & 167.47 & -39.80 & 2159.31 \\
\hline \multicolumn{7}{|c|}{ Addendum } \\
\hline $\begin{array}{c}\tilde{R} \\
(\text { see Row 1) } \\
\end{array}$ & \multicolumn{2}{|c|}{$\begin{array}{c}\text { non-censored } \\
\text { obs. }=1342 \\
\end{array}$} & \multicolumn{2}{|c|}{$\begin{array}{c}\text { disabled } \\
\text { obs. }=40\end{array}$} & \multicolumn{2}{|c|}{$\begin{array}{l}\text { other censored } \\
\text { obs. } \underline{c} /=252\end{array}$} \\
\hline $\begin{array}{c}\tilde{R} \text { winsorized } \\
(\text { see Row } 2)\end{array}$ & \multicolumn{2}{|c|}{$\begin{array}{c}\text { non-censored } \\
\text { obs. }=1317\end{array}$} & \multicolumn{2}{|c|}{$\begin{array}{c}\text { disabled } \\
\text { obs. }=39\end{array}$} & \multicolumn{2}{|c|}{$\begin{array}{c}\text { other censored } \\
\text { obs. } \underline{c}=245\end{array}$} \\
\hline
\end{tabular}

Source: see text. Original HRS cohort. Unweighted. Sample size=1634. Winsorized sample size $($ see text $)=1601$.

(a) Retirement age corrected for selection — see (40).

(b) "Employer-related pension" includes both DB and DC - see text.

(c) Includes those not retiring within sample. 
2, the system is over-identified, and the Wald test in Tables $2 \mathrm{~A}-\mathrm{C}$ tests the validity of the over-identifying restriction.

The first-stage estimates of $\gamma^{R}$ are negative and close to 0 . They are qualitatively similar to LS [2012], although slightly larger in absolute size. In all 6 trials, they are statistically significantly below 0 at the $10 \%$ level with a two-tailed test. The stage-1 estimates of $\gamma^{A}$ are qualitatively similar to the estimates of $\gamma^{R}$, though they are closer to 0 in all cases. In no case does a Wald test of the hypothesis

$$
\mathcal{H}_{0}: \gamma^{R}=\gamma^{A}
$$

yield a statistically significant rejection. ${ }^{15}$ That is encouraging: while the life-cycle model is often estimated from one or the other of labor supply or saving behavior, it is an important tool for policy analysis of both variables. As such, it should be able to explain them simultaneously. In Table 2, our model demonstrates an ability to do so.

Looking at the stage-2 outcomes, the constrained estimate $\gamma=\gamma^{R}=\gamma^{A}$ is significantly different from 0 at the $1 \%$ significance level in all 6 trials. In other words, the analysis strongly rejects separable preferences for consumption and leisure. The constrained estimate resembles the corresponding Stage-1 estimate of $\gamma^{R}$ much more closely than $\gamma^{A}$ in every case. Winsorization makes surprisingly little difference.

Finally, our analysis checks for local maxima to the optimal retirement problem. We do indeed find local maxima in $5-10 \%$ of the cases. For example, in the first column of Table 2A, multiple local maxima arise in 112 of the 1634 cases.

Discussion. One innovation of our formulation is that it emphasizes the importance to households of both consumption expenditure and leisure. Early empirical findings seemed to suggest that households often incurred a large decrease in consumption expenditure after retirement - which was thought to be evidence of non-optimal behavior (e.g., Berheim et al. [2001] and others). Proposition 1 shows that with our specification of preferences in which consumption expenditure and leisure have non-separable roles - a discontinuous (permanent) change in consumption expenditure at retirement is fully consistent with optimality. In particular, households may plan for higher consumption before retirement, in order to compensate themselves for scarce leisure prior to retirement relative to the abundance thereafter. The estimates of $\beta_{4}$ in Table $2 \mathrm{~A}-\mathrm{C}$ suggests a drop in consumption expenditure of about $8 \%$ after retirement on average. The fact that a $99 \%$ confidence interval for $\widehat{\gamma}^{c}$ does not include 0 reinforces the importance of the role of leisure.

Our estimate of $\gamma$, in turn, specifies the intertemporal elasticity of substitution, $I E S=1 /(1-\gamma)$. The IES is important for analysis of tax changes, risk aversion, liquidity constraints, etc. A life-cycle model with fully insured uncertainty often cannot estimate the IES if retirement is exogenous. That would be true for our formulation: $\beta \in R^{4}$ would fully determine a household's wealth accumulation, and (46) could not identify $\gamma$. With endogenous retirement, on the other hand, identification is feasible. Suppose our CEX data shows, for instance, $\beta=-0.08$ and, as is common in the literature, $\gamma<0$. Then

15 Because our corrections for selection in Step 2 leave the errors in the HRS equations heteroscedastic, this subsection presents only White standard errors. Likelihood ratio tests are generally unavailable in these circumstances. 
Table 2A. Structural Model Regression Outcomes with

Stochastic Process for Disability having $\lambda=0.01$ and $\bar{S}=50$ :

Estimated Parameter (Std. Error/T-Stat.)

\begin{tabular}{|c|c|c|c|c|}
\hline \multirow{2}{*}{ Variable } & \multicolumn{2}{|c|}{ Original Sample } & \multicolumn{2}{|c|}{ Winsorized Sample } \\
\hline & Stage 1 & Stage 2 & Stage 1 & Stage 2 \\
\hline$\beta_{1}=\frac{r-\rho}{1-\gamma}$ & $\begin{array}{c}0.0264^{* * *} \\
(0.0008 / 34.5727) \\
\end{array}$ & $\begin{array}{c}0.0272^{* * *} \\
(0.0006 / 41.9929) \\
\end{array}$ & $\begin{array}{c}0.0264^{* * *} \\
(0.0008 / 34.5727) \\
\end{array}$ & $\begin{array}{c}0.0272^{* * *} \\
(0.0006 / 45.1827) \\
\end{array}$ \\
\hline$\beta_{2}=\xi^{S}$ & $\begin{array}{c}0.3351^{* * *} \\
(0.0523 / 6.4108) \\
\end{array}$ & $\begin{array}{c}0.3351^{* * *} \\
(0.0491 / 6.8244) \\
\end{array}$ & $\begin{array}{c}0.3351^{* * *} \\
(0.0523 / 6.4108) \\
\end{array}$ & $\begin{array}{c}0.3353^{* * *} \\
(0.0482 / 6.9583) \\
\end{array}$ \\
\hline$\beta_{3}=\xi^{K}$ & $\begin{array}{c}0.3372^{* * *} \\
(0.0181 / 18.6690) \\
\end{array}$ & $\begin{array}{c}0.3373^{* * *} \\
(0.0165 / 20.4231) \\
\end{array}$ & $\begin{array}{c}0.3372^{* * *} \\
(0.0181 / 18.6690) \\
\end{array}$ & $\begin{array}{c}0.3377^{* * *} \\
(0.0158 / 21.3278) \\
\end{array}$ \\
\hline$\beta_{4}=\frac{\gamma}{1-\gamma} \cdot \ln (\omega)$ & $\begin{array}{c}-0.0831^{* *} \\
(0.0370 /-2.2482) \\
\end{array}$ & $\begin{array}{c}-0.0830^{* * *} \\
(0.0218 /-3.8153) \\
\end{array}$ & $\begin{array}{c}-0.0831^{* *} \\
(0.0370 /-2.2482) \\
\end{array}$ & $\begin{array}{c}-0.0817^{* * *} \\
(0.0086 /-9.4917) \\
\end{array}$ \\
\hline$\gamma$ & $\mathrm{NA}$ & $\begin{array}{c}-0.2171^{* * *} \\
(0.0245 /-8.8703) \\
\end{array}$ & NA & $\begin{array}{c}-0.2174^{* * *} \\
(0.0038 /-5.7157)\end{array}$ \\
\hline$\gamma^{R}$ & $\begin{array}{c}-0.2179^{*} \\
(0.1150 /-1.8940) \\
\end{array}$ & $\mathrm{NA}$ & $\begin{array}{c}-0.2187^{*} \\
(0.1156 /-1.8925) \\
\end{array}$ & NA \\
\hline$\gamma^{A}$ & $\begin{array}{c}-0.0906^{* *} \\
(0.0449 /-2.0179)\end{array}$ & NA & $\begin{array}{c}-0.1382^{* *} \\
(0.0678 /-2.0375)\end{array}$ & $\mathrm{NA}$ \\
\hline$\# \mathrm{Obs}$ & 4033 & 4033 & 3967 & 3967 \\
\hline Criterion $\mathcal{S}(\theta, \hat{V})$ & 0.0000 & 11.6044 & 0.0000 & 4.1428 \\
\hline \multicolumn{5}{|c|}{ Addendum: Statistic for Wald Test of Hypothesis (50) } \\
\hline$\gamma^{R}-\gamma^{A}$ & $\begin{array}{c}-0.1273 \\
(0.0816 /-1.5595) \\
\end{array}$ & NA & $\begin{array}{c}-0.0805 \\
(0.0694 /-1.1604) \\
\end{array}$ & NA \\
\hline
\end{tabular}

Source: see text. Significant at ${ }^{*} 10 \%,{ }^{* *} 5 \%,{ }^{* * *} 1 \%$ level (based on asymptotic distribution). 
Table 2B. Structural Model Regression Outcomes with

Stochastic Process for Disability having $\lambda=0.02$ and $\bar{S}=60$ :

Estimated Parameter (Std. Error/T-Stat.)

\begin{tabular}{|c|c|c|c|c|}
\hline \multirow{2}{*}{ Variable } & \multicolumn{2}{|c|}{ Original Sample } & \multicolumn{2}{|c|}{ Winsorized Sample } \\
\hline & Stage 1 & Stage 2 & Stage 1 & Stage 2 \\
\hline$\beta_{1}=\frac{r-\rho}{1-\gamma}$ & $\begin{array}{c}0.0264^{* * *} \\
(0.0008 / 34.5727) \\
\end{array}$ & $\begin{array}{c}0.0272^{* * *} \\
(0.0006 / 42.0767) \\
\end{array}$ & $\begin{array}{c}0.0264^{* * *} \\
(0.0008 / 34.5727) \\
\end{array}$ & $\begin{array}{c}0.0271^{* * *} \\
(0.0006 / 44.3308)\end{array}$ \\
\hline$\beta_{2}=\xi^{S}$ & $\begin{array}{c}0.3351^{* * *} \\
(0.0523 / 6.4108) \\
\end{array}$ & $\begin{array}{c}0.3355^{* * *} \\
(0.0496 / 6.7626) \\
\end{array}$ & $\begin{array}{c}0.3351^{* * *} \\
(0.0523 / 6.4108) \\
\end{array}$ & $\begin{array}{c}0.3354^{* * *} \\
(0.0482 / 6.9593)\end{array}$ \\
\hline$\beta_{3}=\xi^{K}$ & $\begin{array}{c}0.3372^{* * *} \\
(0.0181 / 18.6690) \\
\end{array}$ & $\begin{array}{c}0.3381^{* * *} \\
(0.0167 / 20.2350) \\
\end{array}$ & $\begin{array}{c}0.3372^{* * *} \\
(0.0181 / 18.6690) \\
\end{array}$ & $\begin{array}{c}0.3378^{* * *} \\
(0.0159 / 21.2791) \\
\end{array}$ \\
\hline$\beta_{4}=\frac{\gamma}{1-\gamma} \cdot \ln (\omega)$ & $\begin{array}{c}-0.0831^{* *} \\
(0.0370 /-2.2482) \\
\end{array}$ & $\begin{array}{c}-0.0817^{* * *} \\
(0.0236 /-3.4568) \\
\end{array}$ & $\begin{array}{c}-0.0831^{* *} \\
(0.0370 /-2.2482) \\
\end{array}$ & $\begin{array}{c}-0.0818^{* * *} \\
(0.0099 /-8.2487) \\
\end{array}$ \\
\hline$\gamma$ & NA & $\begin{array}{c}-0.2039^{* * *} \\
(0.0384 /-5.3077) \\
\end{array}$ & NA & $\begin{array}{c}-0.2076^{* * *} \\
(0.0577 /-3.5954)\end{array}$ \\
\hline$\gamma^{R}$ & $\begin{array}{c}-0.2081^{*} \\
(0.1102 /-1.8883) \\
\end{array}$ & $\mathrm{NA}$ & $\begin{array}{c}-0.2086^{*} \\
(0.1106 /-1.8871) \\
\end{array}$ & NA \\
\hline$\gamma^{A}$ & $\begin{array}{c}-0.0876^{*} \\
(0.0523 /-1.6745)\end{array}$ & NA & $\begin{array}{c}-0.1345^{*} \\
(0.0746 /-1.8032)\end{array}$ & NA \\
\hline$\# \mathrm{Obs}$ & 4033 & 4033 & 3967 & 3967 \\
\hline Criterion $\mathcal{S}(\theta, \hat{V})$ & 0.0000 & 10.4231 & 0.0000 & 3.3691 \\
\hline \multicolumn{5}{|c|}{ Addendum: Statistic for Wald Test of Hypothesis (50) } \\
\hline$\gamma^{R}-\gamma^{A}$ & $\begin{array}{c}-0.1205 \\
(0.0873 /-1.3808) \\
\end{array}$ & $\mathrm{NA}$ & $\begin{array}{c}-0.0741 \\
(0.0820 /-0.9043) \\
\end{array}$ & $\mathrm{NA}$ \\
\hline
\end{tabular}

Source: see text. Significant at ${ }^{*} 10 \%,{ }^{* *} 5 \%,{ }^{* * *} 1 \%$ level (based on asymptotic distribution). 


\section{Table 2C. Structural Model Regression Outcomes without Stochastic Process for Disability: $\underline{a} /$ Estimated Parameter (Std. Error/T-Stat.)}

\begin{tabular}{|c|c|c|c|c|}
\hline \multirow{2}{*}{ Variable } & \multicolumn{2}{|c|}{ Original Sample } & \multicolumn{2}{|c|}{ Winsorized Sample } \\
\hline & Stage 1 & Stage 2 & Stage 1 & Stage 2 \\
\hline$\beta_{1}=\frac{r-\rho}{1-\gamma}$ & $\begin{array}{c}0.0264^{* * *} \\
(0.0008 / 34.5727) \\
\end{array}$ & $\begin{array}{c}0.0271^{* * *} \\
(0.0006 / 42.0999) \\
\end{array}$ & $\begin{array}{c}0.0264^{* * *} \\
(0.0008 / 34.5727) \\
\end{array}$ & $\begin{array}{c}0.0272^{* * *} \\
(0.0007 / 44.5864)\end{array}$ \\
\hline$\beta_{2}=\xi^{S}$ & $\begin{array}{c}0.3351^{* * *} \\
(0.0523 / 6.4108) \\
\end{array}$ & $\begin{array}{c}0.3351^{* * *} \\
(0.0487 / 6.8783) \\
\end{array}$ & $\begin{array}{c}0.3351^{* * *} \\
(0.0523 / 6.4108) \\
\end{array}$ & $\begin{array}{c}0.3353^{* * *} \\
(0.0480 / 6.9834) \\
\end{array}$ \\
\hline$\beta_{3}=\xi^{K}$ & $\begin{array}{c}0.3372^{* * *} \\
(0.0181 / 18.6690) \\
\end{array}$ & $\begin{array}{c}0.3373^{* * *} \\
(0.0164 / 20.6284) \\
\end{array}$ & $\begin{array}{c}0.3372^{* * *} \\
(0.0181 / 18.6690) \\
\end{array}$ & $\begin{array}{c}0.3376^{* * *} \\
(0.0158 / 21.3926) \\
\end{array}$ \\
\hline$\beta_{4}=\frac{\gamma}{1-\gamma} \cdot \ln (\omega)$ & $\begin{array}{c}-0.0831^{* *} \\
(0.0370 /-2.2482)\end{array}$ & $\begin{array}{c}-0.0829^{* * *} \\
(0.0198 /-4.1829) \\
\end{array}$ & $\begin{array}{c}-0.0831^{* *} \\
(0.0370 /-2.2482) \\
\end{array}$ & $\begin{array}{c}-0.0817^{* * *} \\
(0.0075 /-10.9670)\end{array}$ \\
\hline$\gamma$ & NA & $\begin{array}{c}-0.1983^{* * *} \\
(0.0239 /-8.3039) \\
\end{array}$ & NA & $\begin{array}{c}-0.1991^{* * *} \\
(0.0370 /-5.3877) \\
\end{array}$ \\
\hline$\gamma^{R}$ & $\begin{array}{c}-0.1995^{*} \\
(0.1060 /-1.8813) \\
\end{array}$ & NA & $\begin{array}{c}-0.2001^{*} \\
(0.1065 /-1.8801)\end{array}$ & NA \\
\hline$\gamma^{A}$ & $\begin{array}{c}-0.0829^{*} \\
(0.0427 /-1.9396) \\
\end{array}$ & NA & $\begin{array}{c}-0.1273^{* *} \\
(0.0640 /-1.9886) \\
\end{array}$ & NA \\
\hline$\# \mathrm{Obs}$ & 4033 & 4033 & 3967 & 3967 \\
\hline Criterion $\mathcal{S}(\theta, \hat{V})$ & 0.0000 & 11.2229 & 0.0000 & 3.7563 \\
\hline \multicolumn{5}{|c|}{ Addendum: Statistic for Wald Test of Hypothesis (50) } \\
\hline$\gamma^{R}-\gamma^{A}$ & $\begin{array}{c}-0.1166 \\
(0.0755 /-1.5441)\end{array}$ & NA & $\begin{array}{c}-0.0728 \\
(0.0640 /-1.1371)\end{array}$ & NA \\
\hline
\end{tabular}

Source: see text. Significant at ${ }^{*} 10 \%,{ }^{* *} 5 \%,{ }^{* * *} 1 \%$ level (based on asymptotic distribution).

(a) SSDI tax remains in place but hazard into disability is 0 . 


$$
[\omega]^{\frac{\gamma}{1-\gamma}}=e^{-0.08} \Leftrightarrow \omega=e^{-0.08 \cdot(1-\gamma) / \gamma} \Leftrightarrow \frac{d \omega}{d \gamma}>0 .
$$

Thus, $\gamma$ farther below 0 means $\omega$ is lower. Since $\omega$ registers the value of the post-retirement increase in leisure, a lower $\omega$ makes the optimal age of retirement higher. Hence, a unique $\gamma$ can match the HRS retirement data in (45). (In turn, we can also identify $\gamma$ from (46): a later retirement age leads to less wealth accumulation at given early age.) Alternative strategies for estimating $\gamma$ often involve modeling uninsured risks and determining $\gamma$ from the corresponding precautionary saving. Although of great interest, such approaches introduce many new complexities - and analyses often, for simplicity, neglect retirement behavior.

In the end, we are able to estimate life-cycle parameters using micro data on both retirement and wealth accumulation. As we do so, we are able to increase the precision of our estimates of $\gamma$.

4. Policy Simulations This paper's main task is incorporating up-to-date data into the estimation of a life-cycle model's parameters, using both retirement and networth variables. Nonetheless, we briefly present policy simulations to illustrate the model's policy relevance and to note how outcomes differ from previous work. Our model is limited to couples and the analysis above studies male retirements, taking female labor force participation as given; thus, our simulations concentrate on male retirement.

As in LS [2012], we examine age-specific, revenue-neutral payroll tax changes. We are interested in potential efficiency gains from raising the OASI payroll tax (on males) with a surtax prior to age $\mathcal{S}_{0}$, and then removing the OASI tax completely at ages $\mathcal{S}_{0}$ and beyond. The idea is to present households with a lower payroll tax on earnings as they enter the stage in life when they might retire, thereby encouraging longer careers. On the other hand, we use a surtax in earlier years to preserve revenue neutrality for the Social Security system. If existing income and other taxes lead households to retire earlier than efficiency would dictate, encouraging longer careers can promote aggregate well-being. By targeting tax reductions to ages when they can affect the margin of household decision, we can hope to enhance overall economic efficiency.

Table 3 presents results using the parameter estimates from Table $2 \mathrm{~A}$, original sample. We consider removing the OASI payroll tax at each individual age from 54 to 68 .

At higher ages, the average gains in labor force participation are small - most households retire long before $\mathcal{S}_{0}$, so the tax reduction has no effect on their behavior. In fact, the payroll surtax does affect the margin of choice of the latter group, causing many to retire earlier than otherwise, rather than later. Since few households benefit from the tax reduction in this case, the surtax can have a very low rate.

At lower vesting ages, the gains in labor force participation are almost an order of magnitude larger. At $\mathcal{S}_{0}=54$, for example, the overall average increase in male participation is 1.27 years. In that simulation, 1579 households out of the 1634 in our sample choose to work longer. The surtax is therefore high, 1.69\%/yr., and the work disincentive correspondingly high for early retirees - though the relevant group numbers only 29 .

LS [2012] show that the major efficiency gains come from higher income tax revenues generated by enhanced participation rates. In fact, the gain per extra year of participation 
Table 3. Simulated Average Male Labor Force Participation Changes for Payroll Tax Increases Prior to Age $\mathcal{S}_{0}$ and OASI-tax Elimination Thereafter (with Overall Budget Neutrality)

\begin{tabular}{|c|c|c|c|c|c|c|}
\hline Age $\mathcal{S}_{0}$ for & Ave. Increase & Payroll & \multicolumn{2}{|c|}{ Retirement Age Increases } & \multicolumn{2}{|c|}{ Retirement Age Decreases } \\
\hline Elimination & Age - All Cases & Ages $<\mathcal{S}_{0}$ & \# Obs. $\underline{a} /$ & Ave. Increase & \# Obs.. / & Ave. Increase \\
\hline 54 & 1.2703 & 0.0169 & 1579 & 1.3168 & 29 & -0.1219 \\
\hline 55 & 1.2287 & 0.0145 & 1541 & 1.3100 & 67 & -0.1639 \\
\hline 56 & 1.1814 & 0.0123 & 1490 & 1.3055 & 118 & -0.1257 \\
\hline 57 & 1.1221 & 0.0104 & 1427 & 1.2971 & 181 & -0.0965 \\
\hline 58 & 1.0583 & 0.0086 & 1360 & 1.2849 & 248 & -0.0730 \\
\hline 59 & 0.9652 & 0.0071 & 1263 & 1.2649 & 345 & -0.0591 \\
\hline 60 & 0.8757 & 0.0058 & 1160 & 1.2551 & 448 & -0.0561 \\
\hline 61 & 0.7797 & 0.0047 & 1047 & 1.2384 & 561 & -0.0402 \\
\hline 62 & 0.6922 & 0.0038 & 946 & 1.2188 & 662 & -0.0331 \\
\hline 63 & 0.5746 & 0.0030 & 827 & 1.1622 & 781 & -0.0284 \\
\hline 64 & 0.4767 & 0.0023 & 724 & 1.1018 & 884 & -0.0213 \\
\hline 65 & 0.3810 & 0.0018 & 639 & 1.0043 & 969 & -0.0198 \\
\hline 66 & 0.2992 & 0.0014 & 528 & 0.9598 & 1080 & -0.0165 \\
\hline 67 & 0.2363 & 0.0010 & 458 & 0.8761 & 1150 & -0.0131 \\
\hline 68 & 0.1868 & 0.0007 & 377 & 0.8389 & 1231 & -0.0090 \\
\hline
\end{tabular}

Source: See text.

(a) Total observations=1634. Total - \# ret. age increases - \# ret. age decreases=\# zeros. 
is about $\$ 10,000$ 2005-dollars. (Other gains, as measured through equivalent variations, are only about $25 \%$ as large.) Extra income taxes flow to the IRS, in practice, but they could, in principle, be shared with the Social Security trust fund. ${ }^{16}$

A surprise is that while labor force participation gains in Table 3 are similar to those in LS [2012, tab. 5] for high vesting ages, they are about $25 \%$ lower at $\mathcal{S}_{0}=54$. One reason for the latter may be that this paper's simulations affect only males, whereas LS [2012] assume that males and females retire together. Another potentially important factor stems from differences in methodology. Namely, LS [2012] use HRS data only through 2002. About half of their sample had not reached retirement and was excluded from the simulation analysis. Those dropped would have tended to be households that retired at older ages. The last 4 columns of our Table 3 show, however, that late retirees tend to increase their participation less from a payroll tax reduction than those who retire earlier. In the present paper's analysis, virtually all careers are complete in sample - and our new simulation methodology preserves all cases, regardless. Thus, at low values of $\mathcal{S}_{0}$, we have a mixture of young retirees, whose retirement ages rise a great deal, and households that retire at older ages, who postpone retirement more modestly in response to the reform. In sum, the higher participation gains in the earlier study may have been biased upward by the limited sample then available.

5. Conclusion This paper re-estimates the life-cycle model of LS [2012] using up-to-date data and improvements in methodology. The new parameter estimates are qualitatively similar to the old, though not exactly the same. We have more observations with which to work, take more extensive precautions to avoid selection problems, and, most importantly, simultaneously estimate retirement and wealth accumulation equations - taking better advantage of the richness of HRS data resources.

Section 4 demonstrates the new model's usefulness in studying a potential policy reform that has attracted attention: we ask, if we make revenue-neutral, age-dependent changes in the OASI payroll tax, are gains in economic efficiency possible? The answer is "yes." By lowering the payroll tax at ages near retirement and raising it earlier, we can encourage longer careers - enhancing efficiency. Our improved parameter estimates can enhance confidence in the overall results.

16 One precendent was that the 1983 Greenspan Commission report on Social Security Reform recommended that the IRS treat up to $50 \%$ of OASDI benefits as taxable income - and that the proceeds be credited to the OASDI Trust funds. That was accomplished — see the Summary of the Social Security Amendments of 1983 (https://www.ssa.gov/history/1983amend.html). 


\section{Bibliography}

[1] Banks, James; and Diamond, Peter, "The Base for Direct Taxation," (2010) Chapter 6 in J. Mirrlees, S. Adam, T. Besley, R. Blundell, S. Bond, R. Chote, M. Gammie, P. Johnson, G. Myles, and J. Poterba (eds). Dimensions of Tax Design: the Mirrlees Review Oxford University Press.

[2] Burtless, Gary; and Quinn, Joseph, "Is Working Longer the Answer for An Aging Workforce?" Center for Retirement Research at Boston College Issue In Brief no. 11, December 2002.

[3] Erosa, Andres; and Gervais, Martin "Optimal Taxation in Life-Cycle Economies," Journal of Economic Theory, vol. 105, no. 2 (2002): 338-369.

[4] Gallant, A. Ronald. Nonlinear Statistical Models. New York: John Wiley \& Sons, 1987.

[5] Goda, Gopi Shah; Shoven, John; and Slavov, Sita. "Removing the Disincentives in Social Security for Long Careers," in Jeffrey Brown, Jeffrey Liebman, and David Wise (eds.), Social Security Policy in a Changing Environment. University of Chicago Press 2009.

[6] Gustman, Alan; and Steinmeier, Thomas L., "Retirement in Dual-Career Families: A Structural Model," Journal of Labor Economics, vol 18, no. 3 (July 2000): 503-545.

[7] Gustman, Alan L.; and, Steinmeier, Thomas L., "Personal Accounts and Family Retirement," Michigan Retirement Research Center working paper WP 2004-067, January 2004.

[8] House, Christopher; Laitner, John; and Stolyarov, Dmitriy, "Trends in the Labor Force Participation of Married Women," Michigan Retirement Research Center working paper WP 2007-171, October 2007.

[9] House, Christopher; Laitner, John; and Stolyarov, Dmitriy, "Valuing Lost Home Production of Dual Earner Couples," International Economic Review, vol. 49, no. 2 (May 2008): 701-736.

[10] Ippolito, Richard A., Pension Plans and Employee Performance. Chicago: The University of Chicago Press, 1997.

[11] Kremer, Michael, "Should Taxes be Independent of Age?," Mimeo, Harvard University Department of Economics, (2002).

[12] Laitner, John; and, Silverman, Dan, "Estimating Life-Cycle Parameters from Consumption Behavior at Retirement," (2005) NBER Working Paper 11163.

[13] Laitner, John; and, Silverman, Dan, "Consumption, Retirement and Social Security: Evaluating the Efficiency of Reform that Encourages Longer Careers," Journal of Public Economics, 96, no. 7-8 (August 2012): 615-634.

[14] Lozachmeur, Jean-Marie, "Optimal Age-Specific Income Taxation," Journal of Public Economic Theory, vol. 8, no. 4 (2006): 697-711.

[15] Weinzierl, Matthew, "The Surprising Power of Age-Dependent Taxes," Review of Economic Studies, 78, no. 4 (October 2011): 1490-1518. 
[16] White, H. L., "Nonlinear Regression on Cross Sectional Data," Econometrica 48, no. 3 (April 1980): 721-746. 
Appendix 


\section{Table A1. HRS Sample}

\begin{tabular}{|c|c|c|}
\hline Row & Restriction & Sample \\
\hline 1 & Original HRS Households & 13,593 \\
\hline 2 & Couples & 5,057 \\
\hline 3 & Currently Married \& First Marriage Both Spouses & 3,140 \\
\hline 4 & Valid Covariates Both Spouses $\underline{a} /$ & 3,057 \\
\hline 5 & Valid Child Information $\underline{b} /$ & 2,679 \\
\hline 6 & Row 5 and Linked SSA Male Earnings Record & 2,499 \\
\hline 7 & Row 5 and Valid Male Earnings Record from Table A2B-D $\underline{c} /$ & 2,448 \\
\hline 8 & Row 5 and Linked SSA Female Earnings Record & 2,553 \\
\hline 9 & Row 5 and Valid Female Earnings Record from Table A3B $\underline{d} /$ & 2,313 \\
\hline 10 & Row 5 and Row 7 and Row 9 & 1,846 \\
\hline \multicolumn{3}{|c|}{ Addendum } \\
\hline 11 & Row 10 and All Variables for Structural Estimation $\underline{e}$ / & 1,634 \\
\hline
\end{tabular}

Source: see text.

(a) "Valid" records must have birth year each spouse, appear in at least one survey wave, each spouse years of education in $[1,24]$, and spousal age difference $\leq 10$.

(b) Valid records must have $\leq 10$ children and ages for each.

(c) Valid male earnings figures must exceed 1000 times year's minimum wage; valid male earning records must have 1 or more earnings figures prior to year before retirement from full-time work.

(d) Valid female earnings figures must exceed 500 times year's minimum wage; valid female earning records must have 1 or more earnings figures prior to year before retirement from full-time work - or survey must verify female never worked.

(e) Exclude males with retirement ages $\leq 50$. 


\begin{tabular}{|c|c|c|c|c|c|c|c|c|}
\hline \multicolumn{9}{|c|}{$\begin{array}{c}\text { Table A2A. Male Earnings Dynamics Model Estimates: } \\
\text { Two Error }(\mu, \epsilon) \text { Components; } \underline{a} / \text { All Ages (including partial retirement) }\end{array}$} \\
\hline & \multicolumn{2}{|c|}{ Education Group 1} & \multicolumn{2}{|c|}{ Education Group 2} & \multicolumn{2}{|c|}{ Education Group 3} & \multicolumn{2}{|c|}{ Education Group 4} \\
\hline Parameter & $\begin{array}{l}\text { Coeffi- } \\
\text { cient }\end{array}$ & $\begin{array}{l}\text { Std Error } \\
\text { [T-Stat] }\end{array}$ & $\begin{array}{c}\text { Coeffi- } \\
\text { cient }\end{array}$ & $\begin{array}{l}\text { Std Error } \\
\text { [T-Stat }]\end{array}$ & $\begin{array}{c}\text { Coeffi- } \\
\text { cient }\end{array}$ & \begin{tabular}{|c|} 
Std Error \\
{$[$ T-Stat $]$}
\end{tabular} & $\begin{array}{l}\text { Coeffi- } \\
\text { cient }\end{array}$ & $\begin{array}{l}\text { Std Error } \\
\text { [T-Stat] }\end{array}$ \\
\hline$\beta_{0}$ & 9.3505 & $\begin{array}{c}0.0219 \\
{[426.6381]}\end{array}$ & 9.6041 & $\begin{array}{c}0.0186 \\
{[516.3639]}\end{array}$ & 9.7200 & $\begin{array}{c}0.0320 \\
{[303.3537]}\end{array}$ & 9.9379 & $\begin{array}{c}0.0321 \\
{[309.8869]}\end{array}$ \\
\hline$\beta_{1}$ & 0.0624 & $\begin{array}{c}0.0010 \\
{[60.7631]} \\
\end{array}$ & 0.0748 & $\begin{array}{c}0.0009 \\
{[80.9095]} \\
\end{array}$ & 0.0811 & $\begin{array}{c}0.0016 \\
{[49.3677]} \\
\end{array}$ & 0.0932 & $\begin{array}{c}0.0016 \\
{[57.9024]} \\
\end{array}$ \\
\hline$\beta_{2}$ & -0.1303 & $\begin{array}{c}0.0019 \\
{[-67.5778]}\end{array}$ & -0.1692 & $\begin{array}{c}0.0019 \\
{[-89.7148]}\end{array}$ & -0.1916 & $\begin{array}{c}0.0036 \\
{[-53.8510]}\end{array}$ & -0.2189 & $\begin{array}{c}0.0035 \\
{[-62.7279]}\end{array}$ \\
\hline$h_{\mu}$ & 2.1299 & $\begin{array}{c}0.0619 \\
{[34.4175]}\end{array}$ & 2.2123 & $\begin{array}{c}0.0588 \\
{[37.6332]}\end{array}$ & 1.8723 & $\begin{array}{c}0.0740 \\
{[25.3102]}\end{array}$ & 1.4929 & $\begin{array}{c}0.0482 \\
{[30.9664]}\end{array}$ \\
\hline \multirow[t]{2}{*}{$h_{\epsilon}$} & 2.3479 & $\begin{array}{c}0.0134 \\
{[175.1504]} \\
\end{array}$ & 2.0640 & \begin{tabular}{|c|}
0.0111 \\
{$[185.5290]$} \\
\end{tabular} & 1.8466 & $\begin{array}{c}0.0164 \\
{[112.8160]} \\
\end{array}$ & 1.6022 & $\begin{array}{c}0.0131 \\
{[122.1963]} \\
\end{array}$ \\
\hline & \multicolumn{8}{|c|}{ Likelihood $(\mathcal{L})$ and sample size } \\
\hline$-\ln (\mathcal{L})$ & \multicolumn{2}{|c|}{$0.134402 \mathrm{E}+05$} & \multicolumn{2}{|c|}{$0.197580 \mathrm{E}+05$} & \multicolumn{2}{|c|}{$0.875512 \mathrm{E}+04$} & \multicolumn{2}{|c|}{$0.129242 \mathrm{E}+05$} \\
\hline individuals $\underline{b} /$ & \multicolumn{2}{|c|}{674} & \multicolumn{2}{|c|}{831} & \multicolumn{2}{|c|}{378} & \multicolumn{2}{|r|}{592} \\
\hline censored obs & \multicolumn{2}{|c|}{5297} & \multicolumn{2}{|c|}{10771} & \multicolumn{2}{|c|}{5514} & \multicolumn{2}{|r|}{10611} \\
\hline \multirow[t]{2}{*}{ uncensored obs } & \multicolumn{2}{|c|}{16376} & \multicolumn{2}{|c|}{18639} & \multicolumn{2}{|c|}{7007} & \multicolumn{2}{|r|}{8476} \\
\hline & \multicolumn{8}{|c|}{ Experience level $\left(x^{*}\right)$ for peak earnings and ratio of peak to starting earnings $\left(y^{*} / y_{0}\right)$} \\
\hline$x^{*}$ & \multicolumn{2}{|c|}{23.9188} & \multicolumn{2}{|c|}{22.0933} & \multicolumn{2}{|c|}{21.1499} & \multicolumn{2}{|c|}{21.2913} \\
\hline$y^{*} / y_{0}$ & \multicolumn{2}{|c|}{2.1079} & \multicolumn{2}{|c|}{2.2841} & \multicolumn{2}{|c|}{2.3564} & \multicolumn{2}{|r|}{2.6972} \\
\hline
\end{tabular}

See text. $h_{\mu}$ is the precision $1 / \sigma_{\mu}$, etc.

(a) $\mu_{i}$ is a random individual effect, $\epsilon_{i t}$ is a random regression error, and the two are assumed independent.

(b) Males with link to SSA earnings and 1 or more usable observations - see Table A1. 
Table A2B. Male Earnings Dynamics Model Estimates:

Two Error $(\mu, \epsilon)$ Components; $\underline{a} /$ Ages Until Year Before Retirement from Full-time Work

\begin{tabular}{|c|c|c|c|c|c|c|c|c|}
\hline & \multicolumn{2}{|c|}{ Education Group 1} & \multicolumn{2}{|c|}{ Education Group 2} & \multicolumn{2}{|c|}{ Education Group 3} & \multicolumn{2}{|c|}{ Education Group 4} \\
\hline Parameter & $\begin{array}{c}\text { Coeffi- } \\
\text { cient }\end{array}$ & $\begin{array}{l}\text { Std Error } \\
\text { [T-Stat] }\end{array}$ & $\begin{array}{c}\text { Coeffi- } \\
\text { cient }\end{array}$ & $\begin{array}{l}\text { Std Error } \\
\text { [T-Stat] }\end{array}$ & \begin{tabular}{|l} 
Coeffi- \\
cient
\end{tabular} & \begin{tabular}{|c} 
Std Error \\
[T-Stat]
\end{tabular} & $\begin{array}{c}\text { Coeffi- } \\
\text { cient }\end{array}$ & $\begin{array}{c}\text { Std Error } \\
\text { [T-Stat] }\end{array}$ \\
\hline$\beta_{0}$ & 9.3453 & $\begin{array}{c}0.0221 \\
{[422.8266]}\end{array}$ & 9.6056 & $\begin{array}{c}0.0188 \\
{[512.0259]}\end{array}$ & 9.7175 & $\begin{array}{c}0.0321 \\
{[303.1044]}\end{array}$ & 9.9325 & $\begin{array}{c}0.0321 \\
{[309.3079]}\end{array}$ \\
\hline$\beta_{1}$ & 0.0627 & $\begin{array}{c}0.0010 \\
{[60.4179]}\end{array}$ & 0.0748 & $\begin{array}{c}0.0009 \\
{[80.2951]}\end{array}$ & 0.0818 & $\begin{array}{c}0.0017 \\
{[49.5735]}\end{array}$ & 0.0931 & $\begin{array}{c}0.0016 \\
{[57.9064]}\end{array}$ \\
\hline$\beta_{2}$ & -0.1309 & $\begin{array}{c}0.0019 \\
{[-67.1948]}\end{array}$ & -0.1692 & $\begin{array}{c}0.0019 \\
{[-88.9938]}\end{array}$ & -0.1935 & $\begin{array}{c}0.0036 \\
{[-53.9985]}\end{array}$ & -0.2178 & $\begin{array}{c}0.0035 \\
{[-62.4378]}\end{array}$ \\
\hline$h_{\mu}$ & 2.1357 & $\begin{array}{c}0.0627 \\
{[34.0623]}\end{array}$ & 2.2038 & $\begin{array}{c}0.0587 \\
{[37.5237]} \\
\end{array}$ & 1.8754 & $\begin{array}{c}0.0742 \\
{[25.2666]} \\
\end{array}$ & 1.4968 & $\begin{array}{c}0.0485 \\
{[30.8455]}\end{array}$ \\
\hline \multirow[t]{2}{*}{$h_{\epsilon}$} & 2.3439 & $\begin{array}{c}0.0135 \\
{[173.6513]}\end{array}$ & 2.0600 & $\begin{array}{c}0.0112 \\
{[184.5367]}\end{array}$ & 1.8462 & $\begin{array}{c}0.0164 \\
{[112.5851]}\end{array}$ & 1.6124 & $\begin{array}{c}0.0133 \\
{[121.6694]}\end{array}$ \\
\hline & \multicolumn{8}{|c|}{ Likelihood $(\mathcal{L})$ and sample size } \\
\hline$-\ln (\mathcal{L})$ & \multicolumn{2}{|c|}{$0.132128 \mathrm{E}+05$} & \multicolumn{2}{|c|}{$0.196170 \mathrm{E}+05$} & \multicolumn{2}{|c|}{$0.872588 \mathrm{E}+04$} & \multicolumn{2}{|c|}{$0.127480 \mathrm{E}+05$} \\
\hline individuals $\underline{b} /$ & \multicolumn{2}{|c|}{661} & \multicolumn{2}{|c|}{823} & \multicolumn{2}{|c|}{377} & \multicolumn{2}{|r|}{587} \\
\hline censored obs & \multicolumn{2}{|c|}{5152} & \multicolumn{2}{|c|}{10726} & \multicolumn{2}{|c|}{5513} & \multicolumn{2}{|r|}{10513} \\
\hline uncensored obs & \multicolumn{2}{|c|}{16093} & \multicolumn{2}{|c|}{18446} & \multicolumn{2}{|c|}{6978} & \multicolumn{2}{|r|}{8400} \\
\hline & \multicolumn{8}{|c|}{ Experience level $\left(x^{*}\right)$ for peak earnings and ratio of peak to starting earnings $\left(y^{*} / y_{0}\right)$} \\
\hline$x^{*}$ & \multicolumn{2}{|c|}{23.9297} & \multicolumn{2}{|c|}{22.1015} & \multicolumn{2}{|c|}{21.1438} & \multicolumn{2}{|c|}{21.3777} \\
\hline$y^{*} / y_{0}$ & \multicolumn{2}{|c|}{2.1164} & \multicolumn{2}{|c|}{2.2852} & \multicolumn{2}{|c|}{2.3748} & \multicolumn{2}{|c|}{2.7058} \\
\hline
\end{tabular}

See text. $h_{\mu}$ is the precision $1 / \sigma_{\mu}$, etc.

(a) $\mu_{i}$ is a random individual effect, $\epsilon_{i t}$ is a random regression error, and the two are assumed independent.

(b) Males with link to SSA earnings and 1 or more usable observations - see Table A1. 


\begin{tabular}{|c|c|c|c|c|c|c|c|c|}
\hline \multicolumn{9}{|c|}{$\begin{array}{l}\text { Table A2C. Male Earnings Dynamics Model Estimates: } \\
\text { Three Error }(\mu, \epsilon, \eta) \text { Components; } ;(\mu, \epsilon, \eta) \text { Independent; } \\
\text { Ages Until Year Before Retirement from Full-time Work }\end{array}$} \\
\hline & \multicolumn{2}{|c|}{ Education Group 1} & \multicolumn{2}{|c|}{ Education Group 2} & \multicolumn{2}{|c|}{ Education Group 3} & \multicolumn{2}{|c|}{ Education Group 4} \\
\hline Parameter & $\begin{array}{l}\text { Coeffi- } \\
\text { cient }\end{array}$ & $\begin{array}{c}\text { Std Error } \\
\text { [T-Stat }]\end{array}$ & $\begin{array}{l}\text { Coeffi- } \\
\text { cient }\end{array}$ & $\begin{array}{l}\text { Std Error } \\
\text { [T-Stat] }\end{array}$ & \begin{tabular}{|c|}
$\begin{array}{c}\text { Coeffi- } \\
\text { cient }\end{array}$ \\
\end{tabular} & \begin{tabular}{|l} 
Std Error \\
[T-Stat]
\end{tabular} & $\begin{array}{c}\text { Coeffi- } \\
\text { cient }\end{array}$ & $\begin{array}{l}\text { Std Error } \\
\text { [T-Stat] }\end{array}$ \\
\hline$\beta_{0}$ & 9.2893 & $\begin{array}{c}0.0242 \\
{[383.2890]}\end{array}$ & 9.5499 & $\begin{array}{c}0.0199 \\
{[480.7305]}\end{array}$ & 9.6602 & $\begin{array}{c}0.0317 \\
{[305.1217]}\end{array}$ & 9.7703 & $\begin{array}{c}0.0299 \\
{[326.2373]}\end{array}$ \\
\hline$\beta_{1}$ & 0.0665 & $\begin{array}{c}0.0012 \\
{[57.1041]}\end{array}$ & 0.0788 & $\begin{array}{l}0.0011 \\
{[70.0171]}\end{array}$ & 0.0831 & $\begin{array}{c}0.0019 \\
{[44.1956]}\end{array}$ & 0.1042 & $\begin{array}{c}0.0018 \\
{[57.6041]}\end{array}$ \\
\hline$\beta_{2}$ & -0.1409 & $\begin{array}{c}0.0020 \\
{[-69.0295]}\end{array}$ & -0.1781 & $\begin{array}{c}0.0019 \\
{[-91.3821]}\end{array}$ & -0.1935 & $\begin{array}{c}0.0036 \\
{[-53.9985]}\end{array}$ & -0.2367 & $\left.\begin{array}{c}0.0036 \\
{[-66.0101]}\end{array}\right]$ \\
\hline$h_{\mu}$ & 1.9171 & $\begin{array}{c}0.0633 \\
{[30.2763]} \\
\end{array}$ & 2.0225 & $\begin{array}{c}0.0590 \\
{[34.2770]}\end{array}$ & 1.8666 & $\begin{array}{c}0.0829 \\
{[22.5093]} \\
\end{array}$ & 1.6196 & $\begin{array}{c}0.0606 \\
{[26.7080]} \\
\end{array}$ \\
\hline$h_{\epsilon}$ & 2.6326 & $\begin{array}{c}0.0154 \\
{[170.9152]} \\
\end{array}$ & 2.3260 & $\begin{array}{l}0.0128 \\
{[182.2719]} \\
\end{array}$ & 2.1463 & $\begin{array}{c}0.0193 \\
{[111.2552]} \\
\end{array}$ & 1.8782 & $\begin{array}{c}0.0156 \\
{[120.7039]} \\
\end{array}$ \\
\hline \multirow[t]{2}{*}{$h_{\eta}$} & 48.2327 & $\begin{array}{c}1.2044 \\
{[40.0471]} \\
\end{array}$ & 37.7855 & $\begin{array}{c}1.0653 \\
{[35.4705]} \\
\end{array}$ & 32.6316 & $\begin{array}{c}1.0332 \\
{[31.5826]} \\
\end{array}$ & 27.4064 & $\begin{array}{c}0.8638 \\
{[31.7289]} \\
\end{array}$ \\
\hline & \multicolumn{8}{|c|}{ Likelihood $(\mathcal{L})$ and sample size } \\
\hline$-\ln (\mathcal{L})$ & \multicolumn{2}{|c|}{$0.119206 \mathrm{E}+05$} & \multicolumn{2}{|c|}{$0.179135 \mathrm{E}+05$} & \multicolumn{2}{|c|}{$0.788414 \mathrm{E}+04$} & \multicolumn{2}{|c|}{$0.115962 \mathrm{E}+05$} \\
\hline individuals $\underline{b} /$ & \multicolumn{2}{|c|}{661} & \multicolumn{2}{|c|}{823} & \multicolumn{2}{|c|}{377} & \multicolumn{2}{|c|}{587} \\
\hline censored obs & \multicolumn{2}{|c|}{5152} & \multicolumn{2}{|c|}{10726} & \multicolumn{2}{|c|}{5513} & \multicolumn{2}{|c|}{10513} \\
\hline \multirow[t]{2}{*}{ uncensored obs } & \multicolumn{2}{|c|}{16093} & \multicolumn{2}{|c|}{18446} & \multicolumn{2}{|c|}{6978} & \multicolumn{2}{|c|}{8400} \\
\hline & \multicolumn{8}{|c|}{ Experience level $\left(x^{*}\right)$ for peak earnings and ratio of peak to starting earnings $\left(y^{*} / y_{0}\right)$} \\
\hline$x^{*}$ & \multicolumn{2}{|c|}{23.6175} & \multicolumn{2}{|c|}{22.1236} & \multicolumn{2}{|c|}{20.5625} & \multicolumn{2}{|c|}{21.9990} \\
\hline$y^{*} / y_{0}$ & \multicolumn{2}{|c|}{2.1943} & \multicolumn{2}{|c|}{2.3914} & \multicolumn{2}{|c|}{2.3504} & \multicolumn{2}{|c|}{3.1444} \\
\hline
\end{tabular}

See text. $h_{\mu}$ is the precision $1 / \sigma_{\mu}$, etc.

(a) $\mu_{i}$ is a random individual effect; $\epsilon_{i t}$ is a random regression error; and, $\eta_{i}$ is a second random individual effect, which enters the model multiplying years of work experience.

(b) Males with link to SSA earnings and 1 or more usable observations - see Table A1. 
Table A2D. Male Earnings Dynamics Model Estimates:

Three Error $(\mu, \epsilon, \eta)$ Components; $\underline{a} / \epsilon$ Independent; $(\mu, \eta)$ Bivariate Normal with Correlation Coefficient $\rho$; Ages Until Year Before Retirement from Full-time Work

\begin{tabular}{|c|c|c|c|c|c|c|c|c|}
\hline & \multicolumn{2}{|c|}{ Education Group 1} & \multicolumn{2}{|c|}{ Education Group 2} & \multicolumn{2}{|c|}{ Education Group 3} & \multicolumn{2}{|c|}{ Education Group 4} \\
\hline Parameter & $\begin{array}{l}\text { Coeffi- } \\
\text { cient }\end{array}$ & \begin{tabular}{|c|} 
Std Error \\
[T-Stat]
\end{tabular} & $\begin{array}{l}\text { Coeffi- } \\
\text { cient }\end{array}$ & \begin{tabular}{|c|} 
Std Error \\
[T-Stat]
\end{tabular} & $\begin{array}{c}\text { Coeffi- } \\
\text { cient }\end{array}$ & \begin{tabular}{|c|} 
Std Error \\
[T-Stat]
\end{tabular} & \begin{tabular}{|l} 
Coeffi- \\
cient
\end{tabular} & $\begin{array}{c}\text { Std Error } \\
\text { [T-Stat] }\end{array}$ \\
\hline$\beta_{0}$ & 9.2718 & $\begin{array}{c}0.0264 \\
{[350.9990]}\end{array}$ & 9.5482 & $\begin{array}{c}0.0211 \\
{[452.2729]}\end{array}$ & 9.6604 & \begin{tabular}{|c|}
0.0327 \\
{$[295.8525]$}
\end{tabular} & 9.7674 & $\begin{array}{c}0.0309 \\
{[315.7959]}\end{array}$ \\
\hline$\beta_{1}$ & 0.0674 & $\begin{array}{c}0.0012 \\
{[56.0699]}\end{array}$ & 0.0798 & $\begin{array}{c}0.0011 \\
{[73.6682]}\end{array}$ & 0.0837 & $\begin{array}{c}0.0017 \\
{[48.1854]}\end{array}$ & 0.1036 & $\begin{array}{c}0.0018 \\
{[58.5346]}\end{array}$ \\
\hline$\beta_{2}$ & -0.1432 & $\begin{array}{c}0.0020 \\
{[-70.1596]}\end{array}$ & -0.1777 & $\begin{array}{c}0.0023 \\
{[-78.0434]}\end{array}$ & -0.2019 & $\begin{array}{c}0.0036 \\
{[-56.6977]}\end{array}$ & -0.2388 & $\begin{array}{c}0.0035 \\
{[-67.8860]}\end{array}$ \\
\hline$h_{\mu}$ & 1.7259 & $\begin{array}{c}0.0609 \\
{[28.3411]} \\
\end{array}$ & 1.9032 & $\begin{array}{c}0.0569 \\
{[33.4654]}\end{array}$ & 1.7985 & $\begin{array}{c}0.0800 \\
{[22.4807]}\end{array}$ & 1.5576 & $\begin{array}{c}0.0597 \\
{[26.0689]}\end{array}$ \\
\hline$h_{\epsilon}$ & 2.6317 & $\begin{array}{c}0.0154 \\
{[171.2687]}\end{array}$ & 2.3215 & $\begin{array}{c}0.0127 \\
{[182.7153]}\end{array}$ & 2.1424 & $\begin{array}{c}0.0192 \\
{[111.3584]}\end{array}$ & 1.8776 & $\begin{array}{c}0.0156 \\
{[120.5168]} \\
\end{array}$ \\
\hline$h_{\eta}$ & 49.6232 & $\begin{array}{l}0.9754 \\
{[50.8766]}\end{array}$ & 39.9546 & $\begin{array}{c}1.3578 \\
{[29.4252]}\end{array}$ & 34.4159 & $\begin{array}{c}1.0823 \\
{[31.7992]}\end{array}$ & 27.4668 & $\begin{array}{c}0.7273 \\
{[37.7640]}\end{array}$ \\
\hline \multirow[t]{2}{*}{$\rho$} & -0.3572 & $\begin{array}{c}0.0313 \\
{[-11.4079]}\end{array}$ & -0.2414 & $\begin{array}{c}0.0224 \\
{[-10.7837]}\end{array}$ & -0.1692 & $\begin{array}{c}0.0298 \\
{[-5.6754]}\end{array}$ & -0.1020 & $\begin{array}{c}0.0221 \\
{[-4.6255]}\end{array}$ \\
\hline & \multicolumn{8}{|c|}{ Likelihood $(\mathcal{L})$ and sample size } \\
\hline$-\ln (\mathcal{L})$ & \multicolumn{2}{|c|}{$0.118632 \mathrm{E}+05$} & \multicolumn{2}{|c|}{$0.178680 \mathrm{E}+05$} & \multicolumn{2}{|c|}{$0.787168 \mathrm{E}+04$} & \multicolumn{2}{|c|}{$0.115865 \mathrm{E}+05$} \\
\hline individuals $\underline{b} /$ & \multicolumn{2}{|c|}{661} & \multicolumn{2}{|c|}{823} & \multicolumn{2}{|c|}{377} & \multicolumn{2}{|r|}{587} \\
\hline censored obs & \multicolumn{2}{|c|}{5152} & \multicolumn{2}{|c|}{10726} & \multicolumn{2}{|c|}{5513} & \multicolumn{2}{|c|}{10513} \\
\hline \multirow[t]{2}{*}{ uncensored obs } & \multicolumn{2}{|c|}{16093} & \multicolumn{2}{|c|}{18446} & \multicolumn{2}{|c|}{6978} & \multicolumn{2}{|c|}{8400} \\
\hline & \multicolumn{8}{|c|}{ Experience level $\left(x^{*}\right)$ for peak earnings and ratio of peak to starting earnings $\left(y^{*} / y_{0}\right)$} \\
\hline$x^{*}$ & \multicolumn{2}{|c|}{23.5447} & \multicolumn{2}{|c|}{22.4468} & \multicolumn{2}{|c|}{20.7205} & \multicolumn{2}{|c|}{21.6840} \\
\hline$y^{*} / y_{0}$ & \multicolumn{2}{|c|}{2.2115} & \multicolumn{2}{|c|}{2.4488} & \multicolumn{2}{|c|}{2.3797} & \multicolumn{2}{|c|}{3.0737} \\
\hline
\end{tabular}

See text. $h_{\mu}$ is the precision $1 / \sigma_{\mu}$, etc.

(a) $\mu_{i}$ is a random individual effect; $\epsilon_{i t}$ is a random regression error; and, $\eta_{i}$ is a second random individual effect, which enters the model multiplying years of work experience.

(b) Males with link to SSA earnings and 1 or more usable observations - see Table A1. 
Table A3A. Female Earnings Dynamics Model Estimates: Two Error $(\mu, \epsilon)$ Components; $\underline{a}$ / All Ages (including partial retirement)

\begin{tabular}{|c|c|c|c|c|c|c|c|c|}
\hline & \multicolumn{2}{|c|}{ Education Group 1} & \multicolumn{2}{|c|}{ Education Group 2} & \multicolumn{2}{|c|}{ Education Group 3} & \multicolumn{2}{|c|}{ Education Group } \\
\hline Parameter & $\begin{array}{l}\text { Coeffi- } \\
\text { cient }\end{array}$ & $\begin{array}{c}\text { Std Error } \\
{[\text { T-Stat }]}\end{array}$ & $\begin{array}{l}\text { Coeffi- } \\
\text { cient }\end{array}$ & $\begin{array}{c}\text { Std Error } \\
{[\text { T-Stat }]}\end{array}$ & $\begin{array}{l}\text { Coeffi- } \\
\text { cient }\end{array}$ & $\begin{array}{c}\text { Std Error } \\
{[\text { T-Stat }]}\end{array}$ & $\begin{array}{l}\text { Coeffi- } \\
\text { cient }\end{array}$ & $\begin{array}{c}\text { Std Error } \\
{[\text { T-Stat }]}\end{array}$ \\
\hline$\beta_{0}$ & 8.7412 & $\begin{array}{c}0.0221 \\
{[395.4140]} \\
\end{array}$ & 9.0134 & $\begin{array}{c}0.0166 \\
{[542.3137]} \\
\end{array}$ & 8.9933 & $\begin{array}{c}0.0252 \\
{[357.5594]} \\
\end{array}$ & 9.1250 & $\begin{array}{c}0.0357 \\
{[255.7884]}\end{array}$ \\
\hline$\beta_{1}$ & 0.0336 & $\begin{array}{c}0.0019 \\
{[17.5985]}\end{array}$ & 0.0219 & $\begin{array}{c}0.0013 \\
{[17.0305]}\end{array}$ & 0.0457 & $\begin{array}{c}0.0019 \\
{[24.1663]}\end{array}$ & 0.0529 & $\begin{array}{c}0.0027 \\
{[19.4310]}\end{array}$ \\
\hline$\beta_{2}$ & -0.0958 & $\begin{array}{c}0.0055 \\
{[-17.3398]}\end{array}$ & -0.0514 & $\begin{array}{c}0.0035 \\
{[-14.7047]}\end{array}$ & -0.1048 & $\begin{array}{c}0.0050 \\
{[-21.1378]}\end{array}$ & -0.1342 & $\begin{array}{c}0.0077 \\
{[-17.5009]}\end{array}$ \\
\hline$h_{\mu}$ & 2.4068 & $\begin{array}{c}0.0864 \\
{[27.8458]} \\
\end{array}$ & 2.2360 & $\begin{array}{c}0.0554 \\
{[40.3472]} \\
\end{array}$ & 2.2493 & $\begin{array}{c}0.0845 \\
{[26.6199]} \\
\end{array}$ & 1.7050 & $\begin{array}{c}0.0700 \\
{[24.3709]}\end{array}$ \\
\hline \multirow[t]{2}{*}{$h_{\epsilon}$} & 2.1203 & $\begin{array}{c}0.0168 \\
{[125.9713]}\end{array}$ & 1.9196 & $\begin{array}{c}0.0098 \\
{[195.5481]}\end{array}$ & 1.8287 & $\begin{array}{c}0.0136 \\
{[134.6536]} \\
\end{array}$ & 1.5977 & $\begin{array}{c}0.0142 \\
{[112.4435]}\end{array}$ \\
\hline & \multicolumn{8}{|c|}{ Likelihood $(\mathcal{L})$ and sample size } \\
\hline$-\ln (\mathcal{L})$ & \multicolumn{2}{|c|}{$0.631154 \mathrm{E}+04$} & \multicolumn{2}{|c|}{$0.171316 \mathrm{E}+05$} & \multicolumn{2}{|c|}{$0.862856 \mathrm{E}+04$} & \multicolumn{2}{|c|}{$0.746174 \mathrm{E}+04$} \\
\hline individuals $\underline{b}$ & \multicolumn{2}{|c|}{522} & \multicolumn{2}{|c|}{1044} & \multicolumn{2}{|c|}{460} & \multicolumn{2}{|c|}{379} \\
\hline censored obs & \multicolumn{2}{|c|}{44} & \multicolumn{2}{|c|}{353} & \multicolumn{2}{|c|}{237} & \multicolumn{2}{|c|}{682} \\
\hline uncensored obs & \multicolumn{2}{|c|}{8468} & \multicolumn{2}{|c|}{20218} & \multicolumn{2}{|c|}{9590} & \multicolumn{2}{|c|}{6781} \\
\hline & \multicolumn{8}{|c|}{ Years experience $\left(x^{*}\right)$ at peak earnings and ratio peak-to-start earnings $\left(y^{*} / y_{0}\right)$} \\
\hline$x^{*}$ & \multicolumn{2}{|c|}{17.5252} & \multicolumn{2}{|c|}{21.3119} & \multicolumn{2}{|c|}{21.7867} & \multicolumn{2}{|c|}{19.7152} \\
\hline$y^{*} / y_{0}$ & \multicolumn{2}{|c|}{1.3419} & \multicolumn{2}{|c|}{1.2632} & \multicolumn{2}{|c|}{1.6448} & \multicolumn{2}{|c|}{1.6848} \\
\hline
\end{tabular}

See text. $h_{\mu}$ is the precision $1 / \sigma_{\mu}$, etc.

(a) $\mu_{i}$ is a random individual effect, $\epsilon_{i t}$ is a random regression error, and the two are assumed independent.

(b) Females with link to SSA earnings and 1 or more usable observations — see Table A1. 
Table A3B. Female Earnings Dynamics Model Estimates:

Two Error $(\mu, \epsilon)$ Components; $\underline{a} /$ Ages Until Year Before Retirement from Full-time Work

\begin{tabular}{|c|c|c|c|c|c|c|c|c|}
\hline & \multicolumn{2}{|c|}{ Education Group 1} & \multicolumn{2}{|c|}{ Education Group 2} & \multicolumn{2}{|c|}{ Education Group 3} & \multicolumn{2}{|c|}{ Education Group 4} \\
\hline Parameter & $\begin{array}{c}\text { Coeffi- } \\
\text { cient }\end{array}$ & $\begin{array}{l}\text { Std Error } \\
\text { [T-Stat] }\end{array}$ & $\begin{array}{c}\text { Coeffi- } \\
\text { cient }\end{array}$ & $\begin{array}{l}\text { Std Error } \\
\text { [T-Stat] }\end{array}$ & $\begin{array}{l}\text { Coeffi- } \\
\text { cient }\end{array}$ & $\begin{array}{c}\text { Std Error } \\
\text { [T-Stat] }\end{array}$ & $\begin{array}{l}\text { Coeffi- } \\
\text { cient }\end{array}$ & \begin{tabular}{|c} 
Std Error \\
[T-Stat]
\end{tabular} \\
\hline$\beta_{0}$ & 8.7366 & $\begin{array}{c}0.0229 \\
{[381.8643]}\end{array}$ & 9.0085 & $\begin{array}{c}0.0168 \\
{[535.8744]}\end{array}$ & 8.9908 & $\begin{array}{c}0.0254 \\
{[354.2812]}\end{array}$ & 9.1244 & $\begin{array}{c}0.0360 \\
{[253.6187]}\end{array}$ \\
\hline$\beta_{1}$ & 0.0339 & $\begin{array}{c}0.0019 \\
{[17.5115]}\end{array}$ & 0.0227 & $\begin{array}{c}0.0013 \\
{[17.5370]}\end{array}$ & 0.0464 & $\begin{array}{c}0.0019 \\
{[24.4712]} \\
\end{array}$ & 0.0532 & $\begin{array}{c}0.0027 \\
{[19.4575]} \\
\end{array}$ \\
\hline$\beta_{2}$ & -0.0959 & $\begin{array}{c}0.0056 \\
{[-17.1736]}\end{array}$ & -0.0530 & $\begin{array}{c}0.0035 \\
{[-15.1250]}\end{array}$ & -0.1064 & $\begin{array}{c}0.0050 \\
{[-21.4063]}\end{array}$ & -0.1346 & $\begin{array}{c}0.0077 \\
{[-17.4927]}\end{array}$ \\
\hline$h_{\mu}$ & 2.3924 & $\begin{array}{c}0.0882 \\
{[27.1176]} \\
\end{array}$ & 2.2521 & $\begin{array}{c}0.0568 \\
{[39.6633]} \\
\end{array}$ & 2.2544 & $\begin{array}{c}0.0856 \\
{[26.3314]} \\
\end{array}$ & 1.7043 & $\begin{array}{c}0.0705 \\
{[24.1835]} \\
\end{array}$ \\
\hline \multirow[t]{2}{*}{$h_{\epsilon}$} & 2.1180 & $\begin{array}{c}0.0171 \\
{[123.6598]} \\
\end{array}$ & 1.9229 & $\begin{array}{c}0.0099 \\
{[194.0847]}\end{array}$ & 1.8304 & $\begin{array}{c}0.0137 \\
{[134.0857]}\end{array}$ & 1.5989 & $\begin{array}{c}0.0143 \\
{[112.0235]} \\
\end{array}$ \\
\hline & \multicolumn{8}{|c|}{ Likelihood $(\mathcal{L})$ and sample size } \\
\hline$-\ln (\mathcal{L})$ & \multicolumn{2}{|c|}{$0.607757 \mathrm{E}+04$} & \multicolumn{2}{|c|}{$0.168052 \mathrm{E}+05$} & \multicolumn{2}{|c|}{$0.853570 \mathrm{E}+04$} & \multicolumn{2}{|c|}{$0.738598 \mathrm{E}+04$} \\
\hline individuals $\underline{b} /$ & \multicolumn{2}{|c|}{489} & \multicolumn{2}{|c|}{1004} & \multicolumn{2}{|c|}{448} & \multicolumn{2}{|c|}{372} \\
\hline censored obs & \multicolumn{2}{|c|}{44} & \multicolumn{2}{|c|}{343} & \multicolumn{2}{|c|}{232} & \multicolumn{2}{|c|}{661} \\
\hline uncensored obs & \multicolumn{2}{|c|}{8147} & \multicolumn{2}{|c|}{19898} & \multicolumn{2}{|c|}{9504} & \multicolumn{2}{|c|}{6727} \\
\hline & \multicolumn{8}{|c|}{ Years experience $\left(x^{*}\right)$ at peak earnings and ratio peak-to-start earnings $\left(y^{*} / y_{0}\right)$} \\
\hline$x^{*}$ & \multicolumn{2}{|c|}{17.6795} & \multicolumn{2}{|c|}{21.3729} & \multicolumn{2}{|c|}{21.8101} & \multicolumn{2}{|c|}{19.7469} \\
\hline$y^{*} / y_{0}$ & \multicolumn{2}{|c|}{1.3497} & \multicolumn{2}{|c|}{1.2742} & \multicolumn{2}{|c|}{1.6585} & \multicolumn{2}{|c|}{1.6903} \\
\hline
\end{tabular}

See text. $h_{\mu}$ is the precision $1 / \sigma_{\mu}$, etc.

(a) $\mu_{i}$ is a random individual effect, $\epsilon_{i t}$ is a random regression error, and the two are assumed independent.

(b) Females with link to SSA earnings and 1 or more usable observations - see Table A1. 


\begin{tabular}{|c|c|c|c|c|c|c|c|c|}
\hline \multicolumn{9}{|c|}{$\begin{array}{l}\text { Table A4A. Reduced-form Tobit for Male Retirement Age: } \\
\text { Male Earnings Regression A2B, Female Earnings Regression A3B, } \\
\text { Exclude Males Ever Self-Employed (1992-2014) }\end{array}$} \\
\hline & \multicolumn{2}{|c|}{$\begin{array}{c}\text { Education } \\
\text { Group } 1\end{array}$} & \multicolumn{2}{|c|}{$\begin{array}{c}\text { Education } \\
\text { Group } 2\end{array}$} & \multicolumn{2}{|c|}{$\begin{array}{c}\text { Education } \\
\text { Group } 3\end{array}$} & \multicolumn{2}{|c|}{$\begin{array}{c}\text { Education } \\
\text { Group } 4\end{array}$} \\
\hline Parameter & $\begin{array}{l}\text { Coeffi- } \\
\text { cient }\end{array}$ & $\begin{array}{l}\text { Std Error } \\
\text { [T-Stat] }\end{array}$ & $\begin{array}{l}\text { Coeffi- } \\
\text { cient }\end{array}$ & $\begin{array}{l}\text { Std Error } \\
{[\text { T-Stat }]}\end{array}$ & $\begin{array}{l}\text { Coeffi- } \\
\text { cient }\end{array}$ & $\begin{array}{l}\text { Std Error } \\
\text { [T-Stat }]\end{array}$ & $\begin{array}{l}\text { Coeffi- } \\
\text { cient }\end{array}$ & $\begin{array}{c}\text { Std Error } \\
{[\text { T-Stat }]}\end{array}$ \\
\hline CONSTANT & 60.3796 & $\begin{array}{c}0.3789 \\
{[159.3706]} \\
\end{array}$ & 61.2747 & $\begin{array}{c}0.2645 \\
{[231.6807]} \\
\end{array}$ & 61.7187 & $\begin{array}{c}0.4321 \\
{[142.8356]} \\
\end{array}$ & 62.5152 & $\begin{array}{c}0.3389 \\
{[184.4390]} \\
\end{array}$ \\
\hline COUPLE AGE DIFF & -0.1026 & $\begin{array}{c}0.1465 \\
{[-0.7002]}\end{array}$ & \begin{tabular}{|l|}
0.1803 \\
\end{tabular} & $\begin{array}{l}0.1161 \\
{[1.5528]}\end{array}$ & -0.0538 & $\begin{array}{c}0.1908 \\
{[-0.2820]}\end{array}$ & 0.1352 & $\begin{array}{c}0.1389 \\
{[0.9734]}\end{array}$ \\
\hline $\mathrm{KID}=1$ & 2.4547 & $\begin{array}{l}2.5407 \\
{[0.9662]}\end{array}$ & -2.9012 & {$\left[\begin{array}{l}1.9207 \\
-1.5105]\end{array}\right.$} & 4.6062 & $\begin{array}{c}4.5892 \\
{[1.0037]}\end{array}$ & 2.3214 & $\begin{array}{l}2.1025 \\
{[1.1041]}\end{array}$ \\
\hline $\mathrm{KID}=2+$ & 2.7931 & $\begin{array}{c}2.2509 \\
{[1.2409]}\end{array}$ & -3.5321 & $\begin{array}{c}1.7271 \\
{[-2.0451]}\end{array}$ & 5.0804 & $\begin{array}{l}4.3192 \\
{[1.1762]}\end{array}$ & 3.3451 & $\begin{array}{c}1.8383 \\
{[1.8197]}\end{array}$ \\
\hline MARRIAGE DUR & -0.2873 & $\begin{array}{c}0.1045 \\
{[-2.7496]}\end{array}$ & 0.0816 & $\begin{array}{l}0.0802 \\
{[1.0169]}\end{array}$ & -0.0810 & $\begin{array}{c}0.1253 \\
{[-0.6467]}\end{array}$ & -0.1587 & $\begin{array}{c}0.0952 \\
{[-1.6677]}\end{array}$ \\
\hline BRIDGE JOB [Y/N] $\underline{a} /$ & 2.1727 & $\begin{array}{l}1.1951 \\
{[1.8181]}\end{array}$ & 0.1253 & $\begin{array}{l}0.7383 \\
{[0.1697]}\end{array}$ & -0.0524 & $\begin{array}{c}1.2254 \\
-0.0428]\end{array}$ & -1.4462 & $\begin{array}{c}0.9404 \\
{[-1.5378]}\end{array}$ \\
\hline MALE $E[\mu] \underline{b} /$ & 1.7368 & $\begin{array}{l}0.9524 \\
{[1.8235]}\end{array}$ & 1.2974 & $\begin{array}{l}0.6417 \\
{[2.0219]}\end{array}$ & 0.4720 & $\begin{array}{l}0.9329 \\
{[0.5060]}\end{array}$ & 1.7589 & $\begin{array}{l}0.6128 \\
{[2.8703]}\end{array}$ \\
\hline FEMALE $E[\mu] \underline{b} /$ & 0.0372 & $\begin{array}{l}0.9430 \\
{[0.0394]}\end{array}$ & -0.6192 & $\begin{array}{c}0.6883 \\
{[-0.8995]}\end{array}$ & 0.1119 & $\begin{array}{l}1.0463 \\
{[0.1070]}\end{array}$ & -0.6944 & $\begin{array}{c}0.7124 \\
{[-0.9747]}\end{array}$ \\
\hline DUMMY 1928 & 9.5929 & $\begin{array}{l}2.7880 \\
{[3.4407]}\end{array}$ & -2.9101 & $\begin{array}{c}2.0069 \\
{[-1.4500]}\end{array}$ & 1.9071 & $\begin{array}{c}3.6015 \\
{[0.5295]}\end{array}$ & 3.6052 & $\begin{array}{l}2.3916 \\
{[1.5075]}\end{array}$ \\
\hline DUMMY 1929 & 10.0614 & $\begin{array}{l}2.8124 \\
{[3.5775]}\end{array}$ & -1.7824 & $\begin{array}{c}1.8113 \\
{[-0.9841]}\end{array}$ & 1.7078 & $\begin{array}{c}2.9571 \\
{[0.5775]}\end{array}$ & 1.3468 & $\begin{array}{l}2.4237 \\
{[0.5557]}\end{array}$ \\
\hline DUMMY 1930 & 9.7577 & $\begin{array}{l}2.5429 \\
{[3.8372]}\end{array}$ & -1.9391 & $\begin{array}{c}1.7409 \\
-1.1139]\end{array}$ & 0.2366 & $\begin{array}{l}2.8712 \\
{[0.0824]}\end{array}$ & 2.4930 & $\begin{array}{l}1.8786 \\
{[1.3271]}\end{array}$ \\
\hline DUMMY 1931 & 8.5998 & $\begin{array}{l}\frac{0.0011}{2.5310} \\
{[3.3978]}\end{array}$ & -1.6589 & $\begin{array}{c}1.5937 \\
{[-1.0409]}\end{array}$ & 0.8567 & $\begin{array}{c}{[0.0824]} \\
2.5153 \\
{[0.3406]}\end{array}$ & 1.4422 & $\begin{array}{c}1 . .2211] \\
0.8167]\end{array}$ \\
\hline DUMMY 1932 & 9.6697 & $\begin{array}{l}2.4112 \\
{[4.0103]}\end{array}$ & -2.5718 & $\begin{array}{c}1.5190 \\
{[-1.6931]}\end{array}$ & -3.1901 & $\begin{array}{c}2.4761 \\
{[-1.2884]}\end{array}$ & -0.9531 & $\begin{array}{c}1.7646 \\
{[-0.5401]}\end{array}$ \\
\hline DUMMY 1933 & 4.3448 & $\begin{array}{l}2.3436 \\
{[1.8539]}\end{array}$ & -1.0418 & $\begin{array}{c}1.5334 \\
{[-0.6794]}\end{array}$ & 1.5031 & $\begin{array}{c}2.6360 \\
{[0.5702]}\end{array}$ & 1.1644 & $\begin{array}{c}1.8941 \\
{[0.6147]}\end{array}$ \\
\hline DUMMY 1934 & 7.7844 & $\begin{array}{l}2.4424 \\
{[3.1872]}\end{array}$ & -3.1241 & $\begin{array}{c}1.4959 \\
{[-2.0885]}\end{array}$ & 0.5520 & $\begin{array}{c}2.5224 \\
{[0.2188]}\end{array}$ & 1.7930 & $\begin{array}{l}1.6729 \\
{[1.0718]}\end{array}$ \\
\hline DUMMY 1935 & 6.3913 & $\begin{array}{l}2.3566 \\
{[2.7121]}\end{array}$ & -1.5171 & $\begin{array}{c}1.4866 \\
{[-1.0205]}\end{array}$ & 2.1314 & $\begin{array}{c}2.4512 \\
{[0.8695]}\end{array}$ & 0.4806 & $\begin{array}{c}1.6416 \\
{[0.2928]}\end{array}$ \\
\hline DUMMY 1936 & 7.2513 & $\begin{array}{l}2.4037 \\
{[3.0167]}\end{array}$ & -1.0503 & $\begin{array}{c}1.4094 \\
{[-0.7452]}\end{array}$ & -0.3582 & $\begin{array}{c}2.5555 \\
{[-0.1402]}\end{array}$ & 1.7058 & $\begin{array}{l}1.6985 \\
{[1.0043]}\end{array}$ \\
\hline DUMMY 1937 & 5.8696 & $\begin{array}{l}2.2687 \\
{[2.5872]}\end{array}$ & -0.1835 & $\begin{array}{c}1.4416 \\
{[-0.1273]}\end{array}$ & -1.9795 & $\begin{array}{c}2.3102 \\
{[-0.8569]}\end{array}$ & -1.3490 & $\begin{array}{c}1.6285 \\
{[-0.8283]}\end{array}$ \\
\hline DUMMY 1938 & 8.1973 & $\begin{array}{l}2.3946 \\
{[3.4232]}\end{array}$ & -0.4636 & $\begin{array}{c}1.4418 \\
{[-0.3215]}\end{array}$ & 1.7658 & $\begin{array}{c}2.2787 \\
{[0.7749]}\end{array}$ & 0.7190 & $\begin{array}{l}1.6016 \\
{[0.4490]}\end{array}$ \\
\hline DUMMY 1939 & 7.2189 & $\begin{array}{l}2.4382 \\
{[2.9608]}\end{array}$ & -1.2205 & $\begin{array}{c}1.3436 \\
{[-0.9084]}\end{array}$ & 0.7585 & $\begin{array}{c}2.2071 \\
{[0.3437]}\end{array}$ & 2.0571 & $\begin{array}{l}1.6562 \\
{[1.2421]}\end{array}$ \\
\hline DUMMY 1940 & 6.0403 & $\begin{array}{l}2.4106 \\
{[2.5057]}\end{array}$ & -2.1219 & $\begin{array}{c}1.4426 \\
{[-1.4709]}\end{array}$ & 0.2772 & $\begin{array}{c}2.3871 \\
{[0.1161]}\end{array}$ & 1.4540 & $\begin{array}{l}1.5678 \\
{[0.9274]}\end{array}$ \\
\hline \multirow[t]{2}{*}{$h_{\epsilon} \equiv 1 / \sigma_{\epsilon}$} & 0.1492 & $\begin{array}{c}0.0063 \\
{[23.6765]}\end{array}$ & 0.1848 & $\begin{array}{c}0.0066 \\
{[28.0021]}\end{array}$ & 0.1765 & $\begin{array}{l}0.0100 \\
{[17.7109]}\end{array}$ & 0.1816 & $\begin{array}{c}0.0083 \\
{[21.8895]}\end{array}$ \\
\hline & \multicolumn{8}{|c|}{ Likelihood $(\mathcal{L})$ and sample size } \\
\hline$-\ln (\mathcal{L})$ & \multicolumn{2}{|c|}{$0.980373 \mathrm{E}+03$} & \multicolumn{2}{|c|}{$0.124463 \mathrm{E}+04$} & \multicolumn{2}{|c|}{$0.516244 \mathrm{E}+03$} & \multicolumn{2}{|c|}{$0.787049 \mathrm{E}+03$} \\
\hline households & \multicolumn{2}{|c|}{348} & \multicolumn{2}{|c|}{463} & \multicolumn{2}{|c|}{194} & \multicolumn{2}{|c|}{282} \\
\hline
\end{tabular}

See text.

(a) I.e., male had bridge job after partial retirement.

(b) $\mu$ from Tables A2B and A3B - see text. 
Table A4B. Reduced-form Tobit for Male Retirement Age: Male Earnings Regression A2B, Female Earnings Regression A3B, Include Males Ever Self-Employed (1992-2014)

\begin{tabular}{|c|c|c|c|c|c|c|c|c|}
\hline & \multicolumn{2}{|c|}{$\begin{array}{c}\text { Education } \\
\text { Group } 1\end{array}$} & \multicolumn{2}{|c|}{$\begin{array}{c}\text { Education } \\
\text { Group } 2\end{array}$} & \multicolumn{2}{|c|}{$\begin{array}{c}\text { Education } \\
\text { Group } 3\end{array}$} & \multicolumn{2}{|c|}{$\begin{array}{c}\text { Education } \\
\text { Group } 4\end{array}$} \\
\hline Parameter & $\begin{array}{l}\text { Coeffi- } \\
\text { cient }\end{array}$ & $\begin{array}{c}\text { Std Error } \\
\text { [T-Stat }]\end{array}$ & $\begin{array}{l}\text { Coeffi- } \\
\text { cient }\end{array}$ & $\begin{array}{c}\text { Std Error } \\
{[\text { T-Stat }]}\end{array}$ & $\begin{array}{l}\text { Coeffi- } \\
\text { cient }\end{array}$ & $\begin{array}{l}\text { Std Error } \\
{[\text { T-Stat }]}\end{array}$ & $\begin{array}{l}\text { Coeffi- } \\
\text { cient }\end{array}$ & $\begin{array}{c}\text { Std Error } \\
{[\text { T-Stat }]}\end{array}$ \\
\hline CONSTANT & 61.0806 & \begin{tabular}{|l}
0.3143 \\
{$[194.3119]$}
\end{tabular} & 61.6502 & $\begin{array}{c}0.2287 \\
{[269.5235]}\end{array}$ & 62.2341 & $\begin{array}{c}0.3549 \\
{[175.3697]}\end{array}$ & 62.8088 & $\begin{array}{c}0.2831 \\
{[221.8482]}\end{array}$ \\
\hline COUPLE AGE DIFF & -0.1055 & $\begin{array}{l}0.1148 \\
{[-0.9189]}\end{array}$ & 0.1378 & $\begin{array}{l}0.1026 \\
{[1.3432]}\end{array}$ & -0.0735 & $\begin{array}{l}0.1236 \\
{[-0.5945]}\end{array}$ & -0.0120 & $\begin{array}{l}0.1198 \\
{[-0.1004]}\end{array}$ \\
\hline $\mathrm{KID}=1$ & 1.8025 & $\begin{array}{l}2.1925 \\
{[0.8221]}\end{array}$ & -2.1785 & $\begin{array}{c}1.6266 \\
{[-1.3393]}\end{array}$ & 1.8743 & $\begin{array}{l}2.4999 \\
{[0.7497]}\end{array}$ & 0.5208 & $\begin{array}{l}1.8961 \\
{[0.2747]}\end{array}$ \\
\hline $\mathrm{KID}=2+$ & 2.2175 & $\begin{array}{l}1.9696 \\
{[1.1259]}\end{array}$ & -3.1836 & $\begin{array}{c}1.4192 \\
{[-2.2433]}\end{array}$ & -0.0489 & $\begin{array}{c}2.2825 \\
{[-0.0214]}\end{array}$ & 2.5253 & $\begin{array}{c}1.6988 \\
{[1.4866]}\end{array}$ \\
\hline MARRIAGE DUR & -0.3219 & $\begin{array}{l}0.0896 \\
{[-3.5935]}\end{array}$ & 0.0536 & $\begin{array}{l}0.0713 \\
{[0.7517]}\end{array}$ & -0.0263 & $\begin{array}{l}0.0916 \\
{[-0.2874]}\end{array}$ & -0.0936 & $\begin{array}{l}0.0808 \\
{[-1.1581]}\end{array}$ \\
\hline BRIDGE JOB [Y/N] $\underline{a} /$ & 0.0997 & $\begin{array}{l}{[-3.0950]} \\
0.880 \\
{[0.1122]}\end{array}$ & -0.0003 & $\begin{array}{c}0.5828 \\
{[-0.0006]}\end{array}$ & -0.2199 & $\begin{array}{c}{[-0.2014]} \\
{[-0.2419]}\end{array}$ & -2.2209 & $\begin{array}{c}\frac{1-1.1001]}{0.7013} \\
{[-3.1670]}\end{array}$ \\
\hline EVER SELF-EMPL $\underline{b} /$ & 3.5456 & $\begin{array}{l}0.7550 \\
{[4.6959]}\end{array}$ & 1.3967 & $\begin{array}{c}0.5329 \\
{[2.6210]}\end{array}$ & 1.8425 & $\begin{array}{l}0.8121 \\
{[2.2688]}\end{array}$ & 0.9423 & $\begin{array}{l}0.5965 \\
{[1.5799]}\end{array}$ \\
\hline MALE $E[\mu] \underline{c} /$ & 2.3327 & $\begin{array}{l}0.7741 \\
{[3.0132]}\end{array}$ & 0.9540 & $\begin{array}{l}0.5633 \\
{[1.6936]}\end{array}$ & 0.6117 & $\begin{array}{l}0.7129 \\
{[0.8581]}\end{array}$ & 1.2937 & $\begin{array}{l}0.4537 \\
{[2.8513]}\end{array}$ \\
\hline FEMALE $E[\mu] \underline{c} /$ & -0.7172 & $\begin{array}{c}0.7666 \\
-0.9355]\end{array}$ & -0.3305 & $\begin{array}{c}0.5820 \\
{[-0.5679]}\end{array}$ & 0.6502 & $\begin{array}{l}0.8147 \\
{[0.7981]}\end{array}$ & -0.4047 & $\begin{array}{c}0.5957 \\
{[-0.6794]}\end{array}$ \\
\hline DUMMY 1928 & 9.2002 & $\begin{array}{l}2.3193 \\
{[3.9668]}\end{array}$ & -1.9340 & $\begin{array}{c}1.8579 \\
{[-1.0410]}\end{array}$ & -0.4784 & $\begin{array}{c}2.8106 \\
{[-0.1702]}\end{array}$ & 3.9570 & $\begin{array}{l}2.2231 \\
{[1.7800]}\end{array}$ \\
\hline DUMMY 1929 & 8.3460 & $\begin{array}{l}2.2578 \\
{[3.6965]}\end{array}$ & -0.7374 & $\begin{array}{c}1.5459 \\
{[-0.4770]}\end{array}$ & 0.0352 & $\begin{array}{l}2.5174 \\
{[0.0140]}\end{array}$ & 1.8282 & $\begin{array}{l}2.0646 \\
{[0.8855]}\end{array}$ \\
\hline DUMMY 1930 & 8.2647 & $\begin{array}{l}2.0246 \\
{[4.0822]}\end{array}$ & -0.7773 & $\begin{array}{c}1.5270 \\
{[-0.5091]}\end{array}$ & -2.7912 & $\begin{array}{c}2.3556 \\
{[-1.1849]}\end{array}$ & 3.1288 & $\begin{array}{l}1.7120 \\
{[1.8275]}\end{array}$ \\
\hline DUMMY 1931 & 6.7132 & $\begin{array}{l}1.9631 \\
{[3.4197]}\end{array}$ & -0.9783 & $\begin{array}{c}1.3690 \\
{[-0.7146]}\end{array}$ & -1.1904 & $\begin{array}{c}2.0190 \\
{[-0.5896]}\end{array}$ & 1.7015 & $\begin{array}{l}1.4893 \\
{[1.1424]}\end{array}$ \\
\hline DUMMY 1932 & 8.3348 & $\begin{array}{l}1.8685 \\
{[4.4606]}\end{array}$ & -1.1428 & $\begin{array}{c}1.3034 \\
{[-0.8768]}\end{array}$ & -3.2992 & $\begin{array}{c}2.0263 \\
{[-1.6282]}\end{array}$ & -0.0341 & $\begin{array}{c}1.4960 \\
{[-0.0228]}\end{array}$ \\
\hline DUMMY 1933 & 4.0942 & $\begin{array}{l}1.8236 \\
{[2.2452]}\end{array}$ & 0.3412 & $\begin{array}{l}1.2757 \\
{[0.2674]}\end{array}$ & 0.2468 & $\begin{array}{l}2.1394 \\
{[0.1153]}\end{array}$ & 0.8122 & $\begin{array}{l}1.5339 \\
{[0.5295]}\end{array}$ \\
\hline DUMMY 1934 & 6.2301 & $\begin{array}{l}1.8165 \\
{[3.4297]}\end{array}$ & -1.8133 & $\begin{array}{c}1.2557 \\
{[-1.4441]}\end{array}$ & -1.7301 & $\begin{array}{c}2.1294 \\
{[-0.8125]}\end{array}$ & 1.2952 & $\begin{array}{l}1.3756 \\
{[0.9415]}\end{array}$ \\
\hline DUMMY 1935 & 5.6146 & $\begin{array}{l}1.8024 \\
{[3.1151]}\end{array}$ & -0.4955 & $\begin{array}{c}1.2377 \\
{[-0.4004]}\end{array}$ & -1.4487 & $\begin{array}{c}1.9783 \\
{[-0.7323]}\end{array}$ & 2.4470 & $\begin{array}{l}1.3724 \\
{[1.7830]}\end{array}$ \\
\hline DUMMY 1936 & 5.6327 & $\begin{array}{l}1.8871 \\
{[2.9848]}\end{array}$ & -1.0265 & $\begin{array}{c}1.1772 \\
{[-0.8721]}\end{array}$ & -2.0689 & $\begin{array}{c}2.0657 \\
{[-1.0016]}\end{array}$ & 1.2745 & $\begin{array}{l}1.4921 \\
{[0.8542]}\end{array}$ \\
\hline DUMMY 1937 & 5.0527 & $\begin{array}{l}1.7290 \\
{[2.9223]}\end{array}$ & -0.1999 & $\begin{array}{c}1.1868 \\
{[-0.1684]}\end{array}$ & -3.0155 & $\begin{array}{c}1.8788 \\
-1.6050]\end{array}$ & -0.2136 & $\begin{array}{c}1.3525 \\
{[-0.1579]}\end{array}$ \\
\hline DUMMY 1938 & 7.4326 & $\begin{array}{l}1.8629 \\
{[3.9898]}\end{array}$ & -0.0402 & $\begin{array}{c}1.1962 \\
{[-0.0336]}\end{array}$ & 1.1512 & $\begin{array}{l}1.9338 \\
{[0.5953]}\end{array}$ & 1.4479 & $\begin{array}{l}1.3335 \\
{[1.0858]}\end{array}$ \\
\hline DUMMY 1939 & 6.7037 & $\begin{array}{l}1.8218 \\
{[3.6798]}\end{array}$ & -0.7600 & $\begin{array}{c}1.1165 \\
{[-0.6806]}\end{array}$ & -2.0319 & $\begin{array}{c}1.8105 \\
{[-1.1223]}\end{array}$ & 1.0340 & $\begin{array}{l}1.3907 \\
{[0.7435]}\end{array}$ \\
\hline DUMMY 1940 & 4.7300 & $\begin{array}{l}1.7774 \\
{[2.6611]}\end{array}$ & -1.5562 & $\begin{array}{c}1.1951 \\
{[-1.3022]}\end{array}$ & -1.2506 & $\begin{array}{c}1.9542 \\
-0.6399]\end{array}$ & 2.3326 & $\begin{array}{l}1.3255 \\
{[1.7597]}\end{array}$ \\
\hline \multirow[t]{2}{*}{$h_{\epsilon} \equiv 1 / \sigma_{\epsilon}$} & 0.1564 & $\begin{array}{c}0.0058 \\
{[27.1900]}\end{array}$ & 0.1825 & $\begin{array}{c}0.0056 \\
{[32.4409]} \\
\end{array}$ & 0.1777 & $\begin{array}{c}0.0083 \\
{[21.3127]} \\
\end{array}$ & 0.1687 & $\begin{array}{c}0.0060 \\
{[27.9800]}\end{array}$ \\
\hline & \multicolumn{8}{|c|}{ Likelihood $(\mathcal{L})$ and sample size } \\
\hline$-\ln (\mathcal{L})$ & \multicolumn{2}{|c|}{$0.127557 \mathrm{E}+04$} & \multicolumn{2}{|c|}{$0.170326 \mathrm{E}+04$} & \multicolumn{2}{|c|}{$0.749305 \mathrm{E}+03$} & \multicolumn{2}{|c|}{$0.132946 \mathrm{E}+04$} \\
\hline households & \multicolumn{2}{|c|}{462} & \multicolumn{2}{|c|}{631} & \multicolumn{2}{|c|}{282} & \multicolumn{2}{|c|}{471} \\
\hline
\end{tabular}

See text.

(a) I.e., male had bridge job after partial retirement.

(a) I.e., male ever self-employed 1992-2014.

(c) $\mu$ from Tables A2B and A3B - see text. 


\begin{tabular}{|c|c|c|c|c|c|c|c|c|}
\hline \multicolumn{9}{|c|}{$\begin{array}{l}\text { Table A4C. Reduced-form Tobit for Male Retirement Age: } \\
\text { Male Earnings Regression A2D, Female Earnings Regression A3B, } \\
\text { Exclude Males Ever Self-Employed (1992-2014) }\end{array}$} \\
\hline & \multicolumn{2}{|c|}{$\begin{array}{c}\text { Education } \\
\text { Group } 1 \\
\end{array}$} & \multicolumn{2}{|c|}{$\begin{array}{c}\text { Education } \\
\text { Group } 2 \\
\end{array}$} & \multicolumn{2}{|c|}{$\begin{array}{c}\text { Education } \\
\text { Group } 3 \\
\end{array}$} & \multicolumn{2}{|c|}{$\begin{array}{c}\text { Education } \\
\text { Group } 4 \\
\end{array}$} \\
\hline Parameter & $\begin{array}{l}\text { Coeffi- } \\
\text { cient }\end{array}$ & $\begin{array}{l}\text { Std Error } \\
{[\text { T-Stat }]}\end{array}$ & $\begin{array}{c}\text { Coeffi- } \\
\text { cient }\end{array}$ & $\begin{array}{l}\text { Std Error } \\
{[\text { T-Stat }]}\end{array}$ & $\begin{array}{c}\text { Coeffi- } \\
\text { cient }\end{array}$ & $\begin{array}{c}\text { Std Error } \\
{[\text { T-Stat }]}\end{array}$ & \begin{tabular}{|c|} 
Coeffi- \\
cient
\end{tabular} & $\begin{array}{c}\text { Std Error } \\
{[\text { T-Stat }]}\end{array}$ \\
\hline CONSTANT & 60.3432 & $\begin{array}{c}0.3725 \\
{[161.9887]} \\
\end{array}$ & 61.2406 & $\begin{array}{c}0.2565 \\
{[238.7946]} \\
\end{array}$ & 61.6750 & $\begin{array}{c}0.4106 \\
{[150.1952]} \\
\end{array}$ & 62.4870 & $\begin{array}{c}0.3166 \\
{[197.3938]} \\
\end{array}$ \\
\hline COUPLE AGE DIFF & -0.1136 & $\begin{array}{c}0.1439 \\
{[-0.7894]}\end{array}$ & 0.1265 & $\begin{array}{l}0.1129 \\
{[1.1201]}\end{array}$ & -0.0403 & $\begin{array}{l}0.1817 \\
{[-0.2217]}\end{array}$ & 0.0600 & $\begin{array}{l}0.1300 \\
{[0.4614]}\end{array}$ \\
\hline $\mathrm{KID}=1$ & 2.0989 & $\begin{array}{l}2.5036 \\
{[0.8384]}\end{array}$ & -2.8165 & $\begin{array}{c}1.8622 \\
{[-1.5125]}\end{array}$ & 5.7860 & $\begin{array}{l}4.3744 \\
{[1.3227]}\end{array}$ & 2.0934 & $\begin{array}{l}1.9607 \\
{[1.0677]}\end{array}$ \\
\hline $\mathrm{KID}=2+$ & 2.4038 & $\begin{array}{c}2.2180 \\
{[1.0838]}\end{array}$ & -3.0770 & $\begin{array}{c}1.6770 \\
{[-1.8348]}\end{array}$ & 6.2528 & $\begin{array}{r}4.1145 \\
{[1.5197]}\end{array}$ & 3.3250 & $\begin{array}{l}1.7106 \\
{[1.9438]}\end{array}$ \\
\hline MARRIAGE DUR & -0.2419 & $\begin{array}{c}0.1031 \\
{[-2.3471]}\end{array}$ & 0.1105 & $\begin{array}{l}0.0779 \\
{[1.4184]}\end{array}$ & 0.0270 & $\begin{array}{l}0.1219 \\
{[0.2220]}\end{array}$ & -0.0667 & $\begin{array}{c}0.0899 \\
{[-0.7424]}\end{array}$ \\
\hline BRIDGE JOB [Y/N] $\underline{a} /$ & 2.3993 & $\begin{array}{l}1.1788 \\
{[2.0354]}\end{array}$ & 0.6994 & $\begin{array}{l}0.7254 \\
{[0.9642]}\end{array}$ & 0.0918 & $\begin{array}{c}1.1622 \\
{[0.0790]}\end{array}$ & -1.1738 & $\begin{array}{c}0.8796 \\
{[-1.3344]}\end{array}$ \\
\hline MALE $E[\mu] \underline{b} /$ & 1.1603 & $\begin{array}{l}0.8869 \\
{[1.3083]}\end{array}$ & 0.0933 & $\begin{array}{l}0.6221 \\
{[0.1500]}\end{array}$ & -0.4902 & $\begin{array}{c}0.8842 \\
{[-0.5543]}\end{array}$ & -0.3205 & $\begin{array}{c}0.6181 \\
{[-0.5186]}\end{array}$ \\
\hline MALE $E[\eta]^{\underline{b}} /$ & 111.3191 & $\begin{array}{l}31.9508 \\
{[3.4841]}\end{array}$ & 89.9583 & $\begin{array}{l}18.5771 \\
{[4.8424]}\end{array}$ & 85.0896 & $\begin{array}{l}24.4693 \\
{[3.4774]}\end{array}$ & 93.3827 & $\begin{array}{l}15.2988 \\
{[6.1039]}\end{array}$ \\
\hline FEMALE $E[\mu] \underline{b} /$ & -0.1103 & $\begin{array}{c}0.9262 \\
{[-0.1191]}\end{array}$ & -0.6179 & $\begin{array}{c}0.6666 \\
{[-0.9270]}\end{array}$ & 0.2182 & $\begin{array}{l}0.9933 \\
{[0.2197]}\end{array}$ & -1.1039 & $\begin{array}{c}0.6678 \\
{[-1.6531]}\end{array}$ \\
\hline DUMMY 1928 & 9.3305 & $\begin{array}{l}2.7479 \\
{[3.3955]}\end{array}$ & -2.3401 & $\begin{array}{c}1.9482 \\
-1.2012]\end{array}$ & 1.1185 & $\begin{array}{r}3.4213 \\
{[0.3269]}\end{array}$ & 2.5546 & $\begin{array}{l}2.2381 \\
{[1.1414]}\end{array}$ \\
\hline DUMMY 1929 & 9.6813 & $\begin{array}{l}2.7714 \\
{[3.4932]}\end{array}$ & -1.6001 & $\begin{array}{c}1.7578 \\
-0.9103]\end{array}$ & 0.7818 & $\begin{array}{l}2.8118 \\
{[0.2781]}\end{array}$ & -0.1113 & $\begin{array}{c}2.2717 \\
{[-0.0490]}\end{array}$ \\
\hline DUMMY 1930 & 9.0831 & $\begin{array}{r}2.5145 \\
{[3.6123]} \\
\end{array}$ & -1.9283 & $\begin{array}{c}1.6889 \\
{[-1.1417]}\end{array}$ & -0.3705 & $\begin{array}{c}2.7267 \\
{[-0.1359]}\end{array}$ & 1.1321 & $\begin{array}{c}1.7732 \\
{[0.6384]}\end{array}$ \\
\hline DUMMY 1931 & 8.0909 & $\begin{array}{l}2.4958 \\
{[3.2418]}\end{array}$ & -1.2810 & $\begin{array}{c}1.5482 \\
{[-0.8274]}\end{array}$ & 0.4030 & $\begin{array}{l}2.3870 \\
{[0.1688]}\end{array}$ & 0.9976 & $\begin{array}{c}1.6464 \\
{[0.6059]}\end{array}$ \\
\hline DUMMY 1932 & 9.1128 & $\begin{array}{l}2.3834 \\
{[3.8235]}\end{array}$ & -2.2330 & $\begin{array}{c}1.4753 \\
-1.5136]\end{array}$ & -3.6680 & $\begin{array}{c}2.3494 \\
{[-1.5613]}\end{array}$ & -1.8488 & $\begin{array}{c}1.6486 \\
{[-1.1214]}\end{array}$ \\
\hline DUMMY 1933 & 3.9579 & $\begin{array}{r}2.3148 \\
{[1.7099]}\end{array}$ & -0.8385 & $\begin{array}{c}1.4887 \\
{[-0.5632]}\end{array}$ & 1.8273 & $\begin{array}{c}2.5021 \\
{[0.7303]}\end{array}$ & 0.5452 & $\begin{array}{c}1.7670 \\
{[0.3085]}\end{array}$ \\
\hline DUMMY 1934 & 7.3538 & $\begin{array}{l}2.4116 \\
{[3.0494]}\end{array}$ & -2.4315 & $\begin{array}{c}1.4589 \\
{[-1.6667]}\end{array}$ & 0.4675 & $\begin{array}{r}2.3865 \\
{[0.1959]}\end{array}$ & 1.1977 & $\begin{array}{c}1.5651 \\
{[0.7653]}\end{array}$ \\
\hline DUMMY 1935 & 5.7348 & $\begin{array}{l}2.3339 \\
{[2.4571]}\end{array}$ & -1.4235 & $\begin{array}{c}1.4435 \\
{[-0.9862]}\end{array}$ & 1.3349 & $\begin{array}{l}2.3230 \\
{[0.5747]}\end{array}$ & -0.0141 & $\begin{array}{c}1.5356 \\
{[-0.0092]}\end{array}$ \\
\hline DUMMY 1936 & 6.5009 & $\begin{array}{l}2.3816 \\
{[2.7296]}\end{array}$ & -0.6184 & $\begin{array}{c}1.3718 \\
{[-0.4508]}\end{array}$ & -0.5424 & $\begin{array}{c}2.4260 \\
{[-0.2236]}\end{array}$ & 0.9088 & $\begin{array}{c}1.5874 \\
{[0.5725]}\end{array}$ \\
\hline DUMMY 1937 & 5.4259 & $\begin{array}{l}2.2425 \\
{[2.4195]}\end{array}$ & -0.1099 & $\begin{array}{c}1.3987 \\
{[-0.0786]}\end{array}$ & -0.9189 & $\begin{array}{c}2.2128 \\
{[-0.4152]}\end{array}$ & -1.2831 & $\begin{array}{c}1.5192 \\
{[-0.8446]}\end{array}$ \\
\hline DUMMY 1938 & 7.5990 & $\begin{array}{l}2.3642 \\
{[3.2142]}\end{array}$ & -0.3381 & $\begin{array}{l}1.4012 \\
{[-0.2413]}\end{array}$ & 1.3546 & $\begin{array}{l}2.1699 \\
{[0.6242]}\end{array}$ & 0.2699 & $\begin{array}{l}1.4935 \\
{[0.1807]}\end{array}$ \\
\hline DUMMY 1939 & 7.1866 & $\begin{array}{r}2.4072 \\
{[2.9854]}\end{array}$ & -0.8848 & $\begin{array}{c}1.3090 \\
{[-0.6760]}\end{array}$ & 1.8537 & $\begin{array}{r}2.1156 \\
{[0.8762]}\end{array}$ & 1.5983 & $\begin{array}{l}1.5480 \\
{[1.0325]}\end{array}$ \\
\hline DUMMY 1940 & 5.6806 & $\begin{array}{l}2.3768 \\
{[2.3901]}\end{array}$ & -1.3082 & $\begin{array}{c}1.4129 \\
-0.9259]\end{array}$ & 0.0088 & $\begin{array}{c}2.2615 \\
{[0.0039]}\end{array}$ & 1.0790 & $\begin{array}{l}1.4624 \\
0.7378]\end{array}$ \\
\hline \multirow[t]{2}{*}{$h_{\epsilon} \equiv 1 / \sigma_{\epsilon}$} & 0.1518 & $\begin{array}{c}0.0064 \\
{[23.6823]}\end{array}$ & 0.1906 & $\begin{array}{l}0.0068 \\
{[28.0138]}\end{array}$ & 0.1858 & $\begin{array}{c}0.0105 \\
{[17.6994]}\end{array}$ & 0.1946 & $\begin{array}{c}0.0089 \\
{[21.9026]}\end{array}$ \\
\hline & \multicolumn{8}{|c|}{ Likelihood $(\mathcal{L})$ and sample size } \\
\hline$-\ln (\mathcal{L})$ & \multicolumn{2}{|c|}{$0.975671 \mathrm{E}+03$} & \multicolumn{2}{|c|}{$0.123222 \mathrm{E}+04$} & \multicolumn{2}{|c|}{$0.508298 \mathrm{E}+03$} & \multicolumn{2}{|c|}{$0.769591 \mathrm{E}+03$} \\
\hline households & \multicolumn{2}{|c|}{348} & \multicolumn{2}{|c|}{463} & \multicolumn{2}{|c|}{194} & \multicolumn{2}{|c|}{282} \\
\hline
\end{tabular}

See text.

(a) I.e., male had bridge job after partial retirement.

(b) $\mu$ and $\eta$ from Tables A2D and A3B - see text. 


\section{Table A4D. Reduced-form Tobit for Male Retirement Age: Male Earnings Regression A2D, Female Earnings Regression A3B, Include Males Ever Self-Employed (1992-2014)}

\begin{tabular}{|c|c|c|c|c|c|c|c|c|}
\hline & \multicolumn{2}{|c|}{$\begin{array}{c}\text { Education } \\
\text { Group } 1\end{array}$} & \multicolumn{2}{|c|}{$\begin{array}{c}\text { Education } \\
\text { Group } 2\end{array}$} & \multicolumn{2}{|c|}{$\begin{array}{c}\text { Education } \\
\text { Group } 3\end{array}$} & \multicolumn{2}{|c|}{$\begin{array}{c}\text { Education } \\
\text { Group } 4\end{array}$} \\
\hline Parameter & $\begin{array}{l}\text { Coeffi- } \\
\text { cient }\end{array}$ & $\begin{array}{l}\text { Std Error } \\
\text { [T-Stat] }\end{array}$ & $\begin{array}{c}\text { Coeffi- } \\
\text { cient }\end{array}$ & $\begin{array}{l}\text { Std Error } \\
{[\text { T-Stat }]}\end{array}$ & $\begin{array}{l}\text { Coeffi- } \\
\text { cient }\end{array}$ & $\begin{array}{l}\text { Std Error } \\
\text { [T-Stat] }\end{array}$ & $\begin{array}{l}\text { Coeffi- } \\
\text { cient }\end{array}$ & $\begin{array}{c}\text { Std Error } \\
{[\text { T-Stat }]}\end{array}$ \\
\hline CONSTANT & 61.0483 & $\begin{array}{c}0.3103 \\
196.7568]\end{array}$ & 61.6260 & \begin{tabular}{|c|}
0.2234 \\
{$[275.8963]$}
\end{tabular} & 62.2155 & $\begin{array}{l}0.3491 \\
{[178.2054]}\end{array}$ & 62.7821 & $\begin{array}{c}0.2691 \\
{[233.3170]}\end{array}$ \\
\hline COUPLE AGE DIFF & -0.1031 & $\begin{array}{c}0.1133 \\
{[-0.9099]}\end{array}$ & 0.0914 & $\begin{array}{l}0.1005 \\
{[0.9096]}\end{array}$ & -0.0855 & $\begin{array}{c}0.1209 \\
{[-0.7078]}\end{array}$ & -0.0815 & $\begin{array}{c}0.1142 \\
{[-0.7141]}\end{array}$ \\
\hline $\mathrm{KID}=1$ & 1.5235 & $\begin{array}{l}2.1699 \\
{[0.7021]}\end{array}$ & -1.9729 & $\begin{array}{c}1.5898 \\
{[-1.2410]}\end{array}$ & 1.6181 & $\begin{array}{l}2.4516 \\
{[0.6600]}\end{array}$ & 0.6081 & $\begin{array}{l}1.7987 \\
{[0.3381]}\end{array}$ \\
\hline $\mathrm{KID}=2+$ & 1.9791 & $\begin{array}{l}\frac{1.9486}{1.0456]} \\
{[1.0156}\end{array}$ & -2.6311 & $\begin{array}{c}1.3918 \\
{[-1.8905]}\end{array}$ & -0.0963 & $\begin{array}{c}2.2341 \\
{[-0.0431]}\end{array}$ & 2.7630 & $\begin{array}{l}1.6087 \\
{[1.7175]}\end{array}$ \\
\hline MARRIAGE DUR & -0.2761 & $\begin{array}{c}0.0892 \\
{[-3.0949]}\end{array}$ & 0.0827 & $\begin{array}{l}0.0699 \\
{[1.1836]}\end{array}$ & 0.0109 & $\begin{array}{l}0.0908 \\
{[0.1203]}\end{array}$ & -0.0213 & $\begin{array}{c}0.0770 \\
{[-0.2762]}\end{array}$ \\
\hline BRIDGE JOB $[\mathrm{Y} / \mathrm{N}] \underline{a} /$ & 0.3298 & $\begin{array}{l}0.8806 \\
{[0.3746]}\end{array}$ & 0.3674 & $\begin{array}{l}0.5739 \\
{[0.6401]}\end{array}$ & -0.3780 & $\begin{array}{c}0.8955 \\
{[-0.4221]}\end{array}$ & -1.9223 & $\begin{array}{c}0.6690 \\
-2.8735]\end{array}$ \\
\hline EVER SELF-EMPL $\underline{b} /$ & 3.8611 & $\begin{array}{l}0.7522 \\
{[5.1331]}\end{array}$ & 1.5684 & $\begin{array}{l}0.5214 \\
{[3.0080]}\end{array}$ & 1.8446 & $\begin{array}{l}0.7982 \\
{[2.3110]}\end{array}$ & 0.9575 & $\begin{array}{l}0.5672 \\
{[1.6881]}\end{array}$ \\
\hline MALE $E[\mu] \underline{c} /$ & 1.6756 & $\begin{array}{l}0.7425 \\
{[2.2566]}\end{array}$ & -0.2047 & $\begin{array}{c}0.5565 \\
{[-0.3678]}\end{array}$ & -0.3110 & $\begin{array}{c}0.7485 \\
{[-0.4155]}\end{array}$ & \begin{tabular}{|l|}
-0.6209 \\
\end{tabular} & $\begin{array}{c}0.4920 \\
{[-1.2619]}\end{array}$ \\
\hline MALE $E[\eta] \underline{c} /$ & 111.9718 & $\begin{array}{l}26.0446 \\
4.2992]\end{array}$ & 71.2566 & $\begin{array}{l}15.9678 \\
4.4625]\end{array}$ & 42.8893 & $\begin{array}{l}18.6340 \\
2.3017]\end{array}$ & 78.8924 & $\begin{array}{l}11.6961 \\
{[6.7452]}\end{array}$ \\
\hline FEMALE $E[\mu] \underline{c} /$ & -0.7293 & 0.7557 & -0.3376 & $\begin{array}{l}0.5675 \\
{[-0.5950]}\end{array}$ & 0.8417 & 0.8041 & -0.4499 & $\begin{array}{c}0.5676 \\
{[-0.7926]}\end{array}$ \\
\hline DUMMY 1928 & 8.8457 & $\begin{array}{l}2.2927 \\
3.8582]\end{array}$ & -2.0318 & $\begin{array}{c}1.8145 \\
-1.1198]\end{array}$ & -0.9833 & $\begin{array}{c}2.7713 \\
-0.3548]\end{array}$ & 2.9777 & $\begin{array}{c}2.1127 \\
{[1.4094]}\end{array}$ \\
\hline DUMMY 1929 & 7.6147 & $\begin{array}{l}2.2425 \\
{[3.3956]}\end{array}$ & -0.8475 & $\begin{array}{c}1.5099 \\
{[-0.5613]}\end{array}$ & -0.4411 & $\begin{array}{c}2.4793 \\
{[-0.1779]}\end{array}$ & 0.7050 & $\begin{array}{l}1.9641 \\
{[0.3590]}\end{array}$ \\
\hline DUMMY 1930 & 7.4002 & $\begin{array}{l}\frac{10.0197}{2.0197} \\
{[3.6639]}\end{array}$ & -1.1737 & $\begin{array}{c}1.4940 \\
{[-0.7856]}\end{array}$ & -3.1948 & $\begin{array}{c}2.3232 \\
{[-1.3752]}\end{array}$ & 1.8039 & $\begin{array}{l}\frac{0.6372}{1.6372} \\
{[1.1018]}\end{array}$ \\
\hline DUMMY 1931 & 6.1997 & $\begin{array}{l}1.9450 \\
{[3.1875]}\end{array}$ & -1.2221 & $\begin{array}{c}1.3390 \\
{[-0.9127]}\end{array}$ & -1.4767 & $\begin{array}{c}1.9870 \\
{[-0.7432]}\end{array}$ & 0.7524 & $\begin{array}{l}1.4165 \\
{[0.5311]}\end{array}$ \\
\hline DUMMY 1932 & 7.6726 & $\begin{array}{l}1.8605 \\
{[4.1240]}\end{array}$ & -1.3461 & $\begin{array}{c}1.2745 \\
{[-1.0562]}\end{array}$ & -3.4860 & $\begin{array}{c}1.9898 \\
{[-1.7519]}\end{array}$ & -1.1800 & $\begin{array}{c}1.4246 \\
{[-0.8283]}\end{array}$ \\
\hline DUMMY 1933 & 3.5357 & $\begin{array}{l}\frac{1.0125}{1.8125} \\
{[1.9507]}\end{array}$ & 0.1148 & $\begin{array}{l}1.2482 \\
{[0.0920]}\end{array}$ & 0.1302 & $\begin{array}{l}2.1054 \\
{[0.0618]}\end{array}$ & 0.0463 & $\begin{array}{l}1.4587 \\
{[0.0317]}\end{array}$ \\
\hline DUMMY 1934 & 5.6366 & $\begin{array}{l}1.8068 \\
{[3.1197]}\end{array}$ & -1.7368 & $\begin{array}{c}1.2280 \\
{[-1.4143]}\end{array}$ & -2.0207 & $\begin{array}{c}2.0942 \\
{[-0.9649]}\end{array}$ & 0.6832 & $\begin{array}{l}1.3077 \\
{[0.5225]}\end{array}$ \\
\hline DUMMY 1935 & 4.9542 & $\begin{array}{l}1.7938 \\
{[2.7618]}\end{array}$ & -0.7017 & $\begin{array}{c}1.2109 \\
{[-0.5795]}\end{array}$ & -2.0682 & $\begin{array}{c}1.9552 \\
{[-1.0578]}\end{array}$ & 1.2763 & $\begin{array}{l}1.3154 \\
{[0.9703]}\end{array}$ \\
\hline DUMMY 1936 & 4.8754 & $\begin{array}{l}1.8813 \\
{[2.5915]}\end{array}$ & -1.1859 & $\begin{array}{c}1.1510 \\
{[-1.0303]}\end{array}$ & -2.4114 & $\begin{array}{c}2.0336 \\
{[-1.1858]}\end{array}$ & 0.7472 & $\begin{array}{l}1.4307 \\
{[0.5223]}\end{array}$ \\
\hline DUMMY 1937 & 4.4535 & $\begin{array}{l}1.7205 \\
{[2.5885]}\end{array}$ & -0.2948 & $\begin{array}{c}1.1596 \\
{[-0.2543]}\end{array}$ & -2.5910 & $\begin{array}{c}1.8559 \\
{[-1.3961]}\end{array}$ & -0.3220 & $\begin{array}{c}1.2871 \\
{[-0.2501]}\end{array}$ \\
\hline DUMMY 1938 & 6.8118 & $\begin{array}{l}1.8479 \\
{[3.6861]}\end{array}$ & -0.3070 & $\begin{array}{c}1.1705 \\
{[-0.2623]}\end{array}$ & 0.9520 & $\begin{array}{l}1.9080 \\
{[0.4990]}\end{array}$ & 1.0461 & $\begin{array}{c}1.2607 \\
{[0.8298]}\end{array}$ \\
\hline DUMMY 1939 & 6.5982 & $\begin{array}{l}1.8049 \\
{[3.6557]}\end{array}$ & -0.8924 & $\begin{array}{c}1.0942 \\
{[-0.8156]}\end{array}$ & -2.0210 & $\begin{array}{c}1.7793 \\
{[-1.1358]}\end{array}$ & 0.7520 & $\begin{array}{l}\frac{0.3206]}{1.3206} \\
{[0.5695]}\end{array}$ \\
\hline DUMMY 1940 & 4.3766 & $\begin{array}{c}1.7592 \\
{[2.4878]}\end{array}$ & -1.2661 & $\begin{array}{c}1.1720 \\
{[-1.0803]}\end{array}$ & -1.4929 & $\begin{array}{c}1.9198 \\
{[-0.7776]}\end{array}$ & 1.8614 & $\begin{array}{l}1.2618 \\
{[1.4752]}\end{array}$ \\
\hline \multirow[t]{2}{*}{$h_{\epsilon} \equiv 1 / \sigma_{\epsilon}$} & 0.1585 & $\begin{array}{c}0.0058 \\
{[27.1854]}\end{array}$ & 0.1869 & $\begin{array}{c}0.0058 \\
{[32.4323]}\end{array}$ & 0.1806 & $\begin{array}{c}0.0085 \\
{[21.2925]}\end{array}$ & 0.1778 & $\begin{array}{c}0.0064 \\
{[27.9510]}\end{array}$ \\
\hline & \multicolumn{8}{|c|}{ Likelihood $(\mathcal{L})$ and sample size } \\
\hline$-\ln (\mathcal{L})$ & \multicolumn{2}{|c|}{$0.127105 \mathrm{E}+04$} & \multicolumn{2}{|c|}{$0.169088 \mathrm{E}+04$} & \multicolumn{2}{|c|}{$0.746014 \mathrm{E}+03$} & \multicolumn{2}{|c|}{$0.130462 \mathrm{E}+04$} \\
\hline households & \multicolumn{2}{|c|}{462} & \multicolumn{2}{|c|}{631} & \multicolumn{2}{|c|}{282} & \multicolumn{2}{|c|}{470} \\
\hline
\end{tabular}

See text.

(a) I.e., male had bridge job after partial retirement.

(b) I.e., male ever self-employed 1992-2014.

(c) $\mu$ and $\eta$ from Tables A2D and A3B - see text. 